\title{
Operation stability analysis of district heating substation from the
}

\section{control perspective}

Yaran Wang a, b, Shijun You a, b, Huan Zhang a, b, Xuejing Zheng a, *, Shen Wei ${ }^{\text {c, }}$ Qingwei Miao a , Wandong Zheng a

${ }^{a}$ School of Environmental Science and Engineering, Tianjin University, Tianjin 300350, PR China

${ }^{b}$ Key Laboratory of Efficient Utilization of Low and Medium Grade Energy, MOE, Tianjin University, Tianjin 300350, PR China

${ }^{c}$ Faculty of Engineering and Environment, Northumbria University, Newcastle upon Tyne NE1 8ST, UK

* Corresponding author. Tel.: +086013512419172; fax: +8602227400832. E-mail addresses: zhengxuejing@tju.edu.cn

\section{Highlights}

$\checkmark$ Oscillatory of flow rate observed in district heating substation

$\checkmark \quad$ Mathematical model describing thermal dynamics of heating substation

$\checkmark$ Control theory based criterion for operation stability of heating substation

$\checkmark$ Conditions that leads to operation instability of district heating substation

$\checkmark$ Controller tuning of the plate heat exchanger to ensure robust stability

\section{Keywords}

District heating substation; Mathematical model; Operation instability; Stability analysis; Feedback control; Plate heat exchanger

\section{Abstract}

Since the heating substation plays a key role in transferring the thermal energy 
from the primary network to the secondary network and controlling the heat output of district heating system to meet the thermal load, high operation performance of heating substation is essential for energy conservation, cost saving and emission reduction. The dynamic operation stability of heating substation is a very important dynamic characteristic of heating substation and largely affects the operation efficiency of district heating system. The operation instability of heating substation mainly manifest as flow rate and pressure oscillations, which will deteriorate the network hydraulic condition, break the network thermal balance, reduce the consumer comfort and increase the energy cost of the pumping system. Since heating substations will easily operate unstably under some conditions, this paper presents a theoretical method to analyze the stability and retune the feedback controller for operation stability of heating substation. Mathematical model of the plate heat exchanger was established and the feedback control theory was adopted to study the operation stability of heating substation. Based on the mathematical model and feedback control theory, a stability criterion was proposed for analyzing the operation stability of district heating substation effectively. The dynamic model of plate heat exchanger was validated with measured data. Simulation results show that controller tuned at certain operating condition can't ensure operation stability of heating substation, when operating condition varies in large range. The stability analysis method proposed in this paper can be applied to analyzing the operation stability and tuning the controller of heating substation to enhance the operation stability. 


\begin{tabular}{|c|c|}
\hline \multicolumn{2}{|l|}{ Nomenclature } \\
\hline$A$ & matrix of state space model \\
\hline$b$ & width of the plate heat exchanger flow channel (m) \\
\hline$B_{1}, B_{2}, B_{3}, B_{4}$ & matrices of linearized state space model \\
\hline C & matrix of linearized state space model \\
\hline$c_{p}$ & specific heat capacity of water $(\mathrm{W} / \mathrm{kg} \cdot \mathrm{K})$ \\
\hline$C_{\mathrm{v}}$ & flow capacity of control valve \\
\hline$C_{N u}$ & the empirical parameter \\
\hline$d$ & distance between neighboring plates (m) \\
\hline$D$ & hydraulic diameter $(\mathrm{m})$ \\
\hline$G(s), G_{d, 1}(s), G_{d, 2}(s)$ & transfer function of linearized plate heat exchanger model \\
\hline$G_{d, 3}(s), G_{d, 4}(s)$ & \\
\hline $\mathrm{i}$ & $\sqrt{-1}$ \\
\hline$k$ & overall heat transfer coefficient $\left(\mathrm{W} / \mathrm{m}^{2} \cdot \mathrm{K}\right)$ \\
\hline$K$ & transfer function of controller \\
\hline$k_{c}$ & controller gain \\
\hline$k_{v}$ & valve gain \\
\hline$l$ & length of flow channel \\
\hline$L(\mathrm{i} \omega)$ & loop transfer function \\
\hline$M$ & number of flow channels in each side \\
\hline$N$ & number of the control volumes in a flow channel \\
\hline$n_{1}, n_{2}$ & the empirical parameter \\
\hline$N u$ & the Nusselt number \\
\hline $\operatorname{Pr}$ & the Prantl number \\
\hline$q$ & volume flow rate $\left(\mathrm{m}^{3} / \mathrm{s}\right)$ \\
\hline$R$ & the rangeability of the valve \\
\hline $\operatorname{Re}$ & the Reynolds number \\
\hline$s$ & the Laplace variable \\
\hline$t$ & time (s) \\
\hline$T$ & temperature $\left({ }^{\circ} \mathrm{C}\right)$ \\
\hline$x$ & coordinate along the flow channel (m) \\
\hline$z$ & controller zero \\
\hline$\lambda$ & heat conductivity coefficient $\left(\mathrm{W} / \mathrm{m}^{2} \cdot \mathrm{K}\right)$ \\
\hline$\mu$ & the dynamic viscosity \\
\hline$\rho$ & density of the water $\left(\mathrm{kg} / \mathrm{m}^{3}\right)$ \\
\hline$\tau$ & time delay of temperature sensor (s) \\
\hline$\delta$ & small deviation \& increment symbol of variable \\
\hline$\omega$ & frequency $(\mathrm{rad} / \mathrm{s})$ \\
\hline
\end{tabular}




\begin{tabular}{|ll|}
\hline Nomenclature & \\
\hline$\Delta x$ & length of a control volume $(\mathrm{m})$ \\
Subscripts & \\
$h$ & high temperature side \\
in & inlet \\
$l$ & low temperature side \\
out & outlet \\
\hline
\end{tabular}

\section{Introduction}

In China, The total energy consumption of district heating systems in northern areas covers $24 \%$ of the total energy cost of building energy systems [1]. Therefore, improving the operation efficiency of district heating system is important to reducing energy cost and enhancing room comfort. In large scale district heating systems, the heating substations are the terminals, which control the heat outputs to the secondary networks. Efficient regulation of the district heating network relies on effective operation and control of the heating substation.

There have been numerous researches on improvement of heating substation efficiency by applying new control strategy. Gustafsson et al. [2] developed a new control approach for indirectly connected district heating substations based on a physical model, which maximizes the $\Delta \mathrm{T}$ of the district heating network. They also verified the control method experimentally through implementation of the control method in a real district heating substation; the results confirms that it is possible to control the radiator system based on the primary supply temperature while maintaining comfort; however, conclusions regarding improvements in $\Delta \mathrm{T}$ were hard to distinguish [3]. Since high return temperature will lead to large amount of overall 
distribution energy cost, the temperature difference faults can be detected and eliminated by using fault detection approaches. Gadd and Werner [4, 5] presented a fault detection based method to achieve low return temperatures in district heating substations.

Modeling the heating substation is important to analyzing and evaluating the operation performance of heating substation. Brand et al. [6] developed a numerical model for heating substation, which takes into consideration the effect of service pipes. With this model, they studied the effects of service pipe on waiting time for DHW, heat loss, and overall cost. Brand et al. [7] also used the commercial software IDA-ICE and Termis to model and analyze various solutions for controlling the redirected bypass flow and evaluated their performance and the effect on the $\mathrm{DH}$ network in heating substation. Kuosa [8] developed a numerical model for a district heating system with ring network, with which the variations of flow rates, pressure losses and overall heat transfer coefficients of plate heat exchanger in heating substation were simulated and analyzed on selected days. Dobos and Abonyi [9] developed the nonlinear dynamic model of the district heating network including the heat exchanger in heating substations, heat production units and pipelines to study the nonlinear model predictive control of district heating network.

Since plate heat exchanger is the core component of heating substation, mathematical modeling and control performance analysis of plate heat exchanger is important to improve the operation efficiency of district heating substation. Feedback control analysis and design of plate heat exchangers have been paid attentions. 
Al-Dawery [10] established a first order model with time delay to suggest the transient responses of a plate heat exchanger, and a fuzzy logic controller of the plate heat exchanger was designed to achieve less settling time and oscillatory behavior. Michel and Kugi [11] developed a control strategy without knowledge of the heat transfer of plate heat exchanger based on controlling the total thermal energy stored in the heat exchanger and a Kalman Filter to estimate the states.

However there were few studies concerning the dynamic operation stability of heating substation, which is a very important dynamic characteristic for heating substation and largely affects the operation efficiency of district heating system. The operation instability of heating substation mainly manifest as flow rate and pressure oscillations, which will deteriorate the network hydraulic condition, break the network thermal balance, reduce the consumer comfort and increase the energy cost of the pumping system. Since heating substations will easily operate unstably under some conditions, this paper presents a theoretical method to analyze the stability and retune the feedback controller for operation stability of heating substation. The theoretical method presented in this paper mainly utilized the techniques developed in feedback control theory [12]. The feedback control theory has been effectively applied to analyze the operation stability and elimination of oscillations in a central heating system using pump control [13]. Tahersima et al. utilized the feedback control theory to study the stability performance and developed a gain scheduling controller of radiator heating system in a room [14]. In our previous work, the control oriented approaches were adopted to establish an accurate low order model of room heating 
112

113

system and propose a two-degrees-of-freedom $H_{\infty}$ loop-shaping controller [15]. Research on the operation stability of district heating system focuses on dynamic variation and fluctuation of flow rates, pressures and temperatures in the district heating network, which is very important and applicable in improving the operating efficiency of the district heating network. In this paper, the operation stability of district heating substation was studied from the control perspective. An analytical tool was developed to analyzing the operation stability of district heating substation.

\section{Control levels of district heating system}

Fig. 1 shows the schematic of district heating system. The hot water is generated from the heat source and delivered to the heating substations by the primary circulation pump along the primary pipelines. The heating substations are usually located near the center of load regions. The main components of a heating substation are the plate heat exchanger, primary control valve, secondary circulation pump and the control system.

In order to provide sufficient thermal energy effectively, the district heating system is usually regulated under three control levels. The first level is named the centralized control; this level functions at the heat sources, which controls the primary supply temperature and the pump speed to meet the total heating load variations of the network. The second level is called the local control; this level functions at each 

pump speed to satisfy the variable heating load of the heat consumers. The secondary supply temperature is controlled by adjusting the control valve of the plate heat exchanger at the primary side. The third level is personal control; this level functions at each radiator, which controls the flow rate of radiator according to the room temperature difference between the desired and value to maintain the room air temperature around the desired value. In district heating system operation, the three control levels work simultaneously to allocate heat to each consumer. Fig. 1 shows the control structure of district heating network. As is shown, local control plays a key role in controlling the heat output of the primary network.

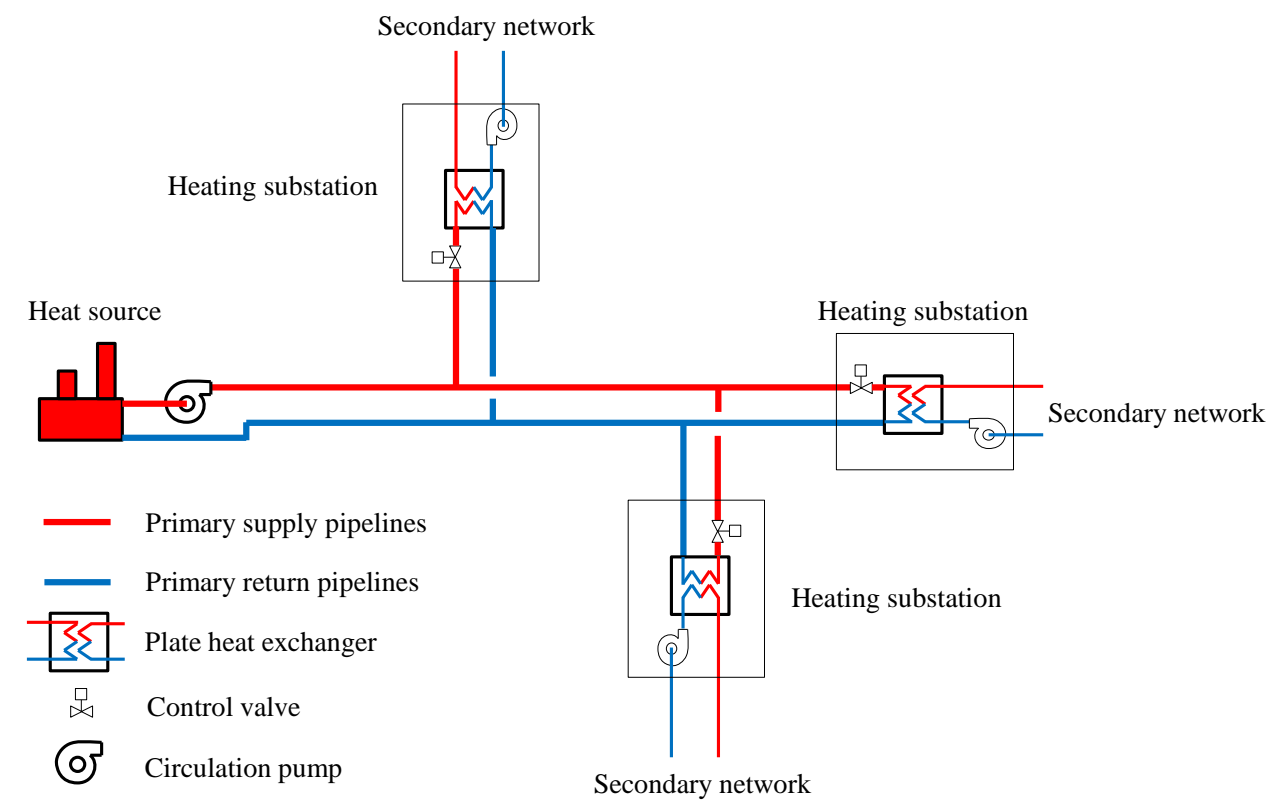




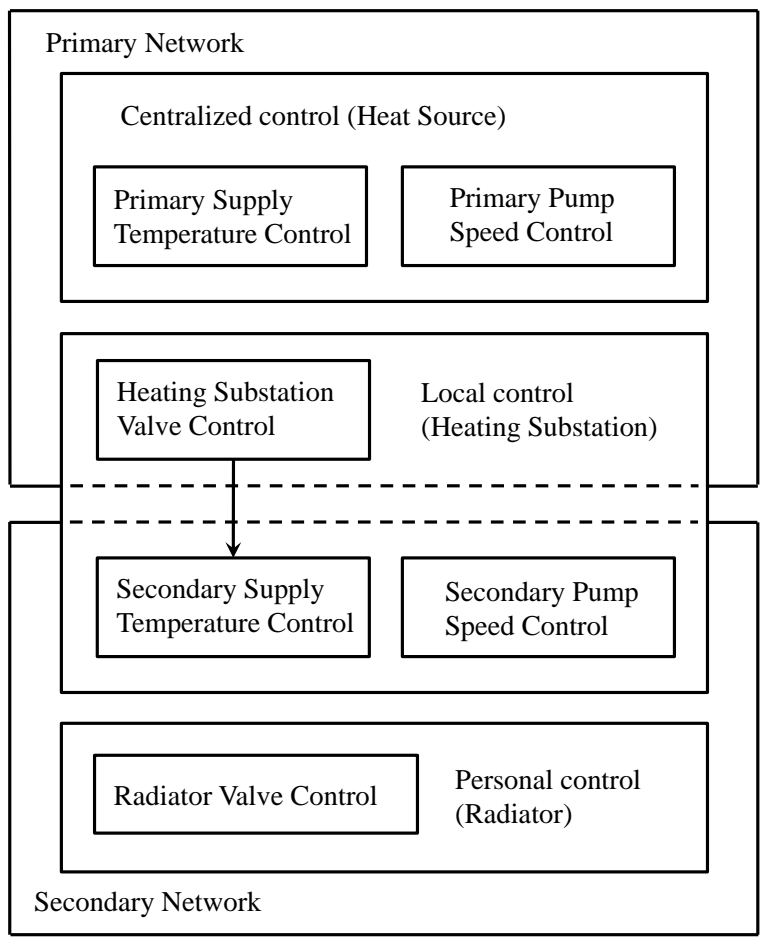

Fig. 2. Control levels of the district heating network.

Fig. 3 shows the schematic of the feedback control structure in heating substation, which composes the main part of the local control. Efficient operation of the heating substation requires the feedback control loop to be stable. However, numerous heating substations are working in unstable conditions, and oscillations of flow rate and pressure always occur. The instability is resulted from the nonlinearities of valve and plate heat exchanger, sensor delay and improperly-tuned controller.

Fig.4 shows the measured primary side flow rate, supply temperature and 157 outdoor temperature of a district heating substation in Tianjin, China. The secondary side of the heating substation is a commercial building with 22 floors. These measured data are to illustrate the operation instability of a district heating substation.

As is shown, oscillation of primary side flow rate occurs when supply temperature is 

network, increase the energy cost of pumping system and reduce the lifetime of control valve. In order to investigate the instability analytically and stabilize the heating substation with properly-tuned controller, mathematical models of the heat exchanger and the feedback controller are established.
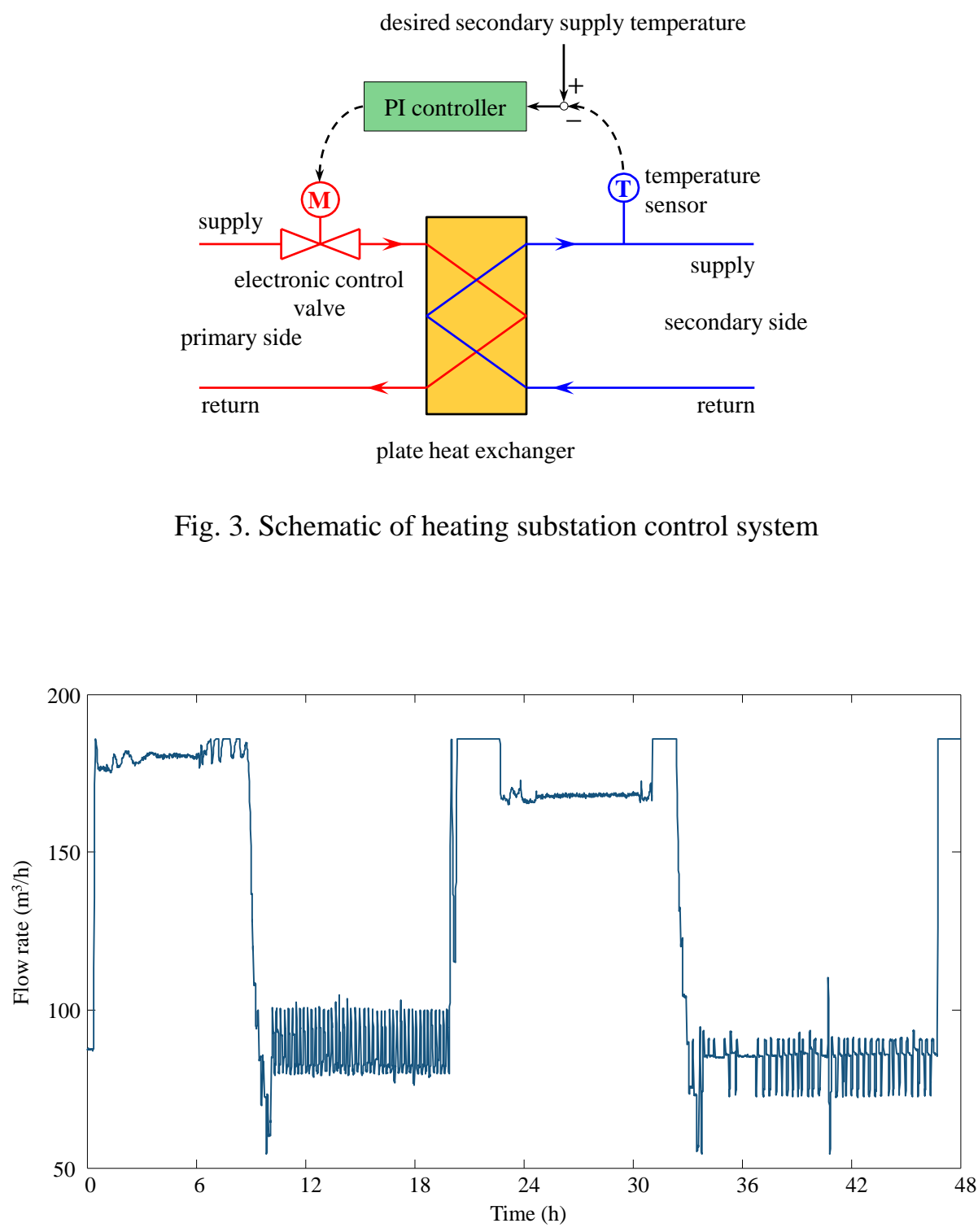


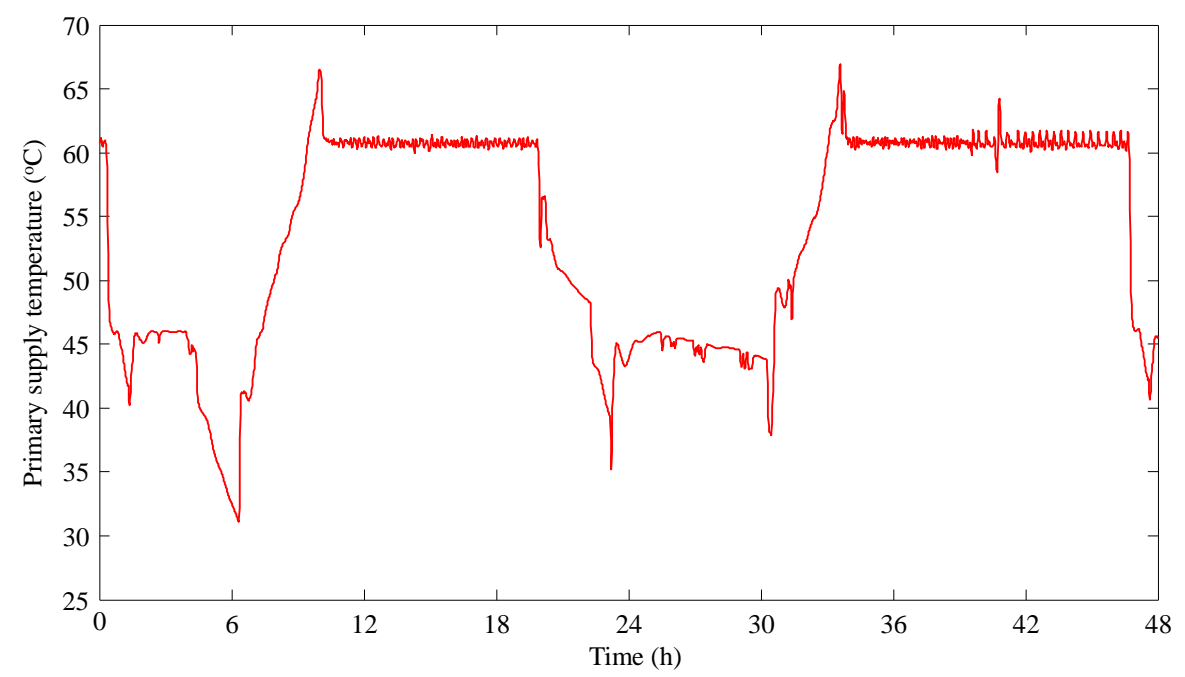

173

174

175

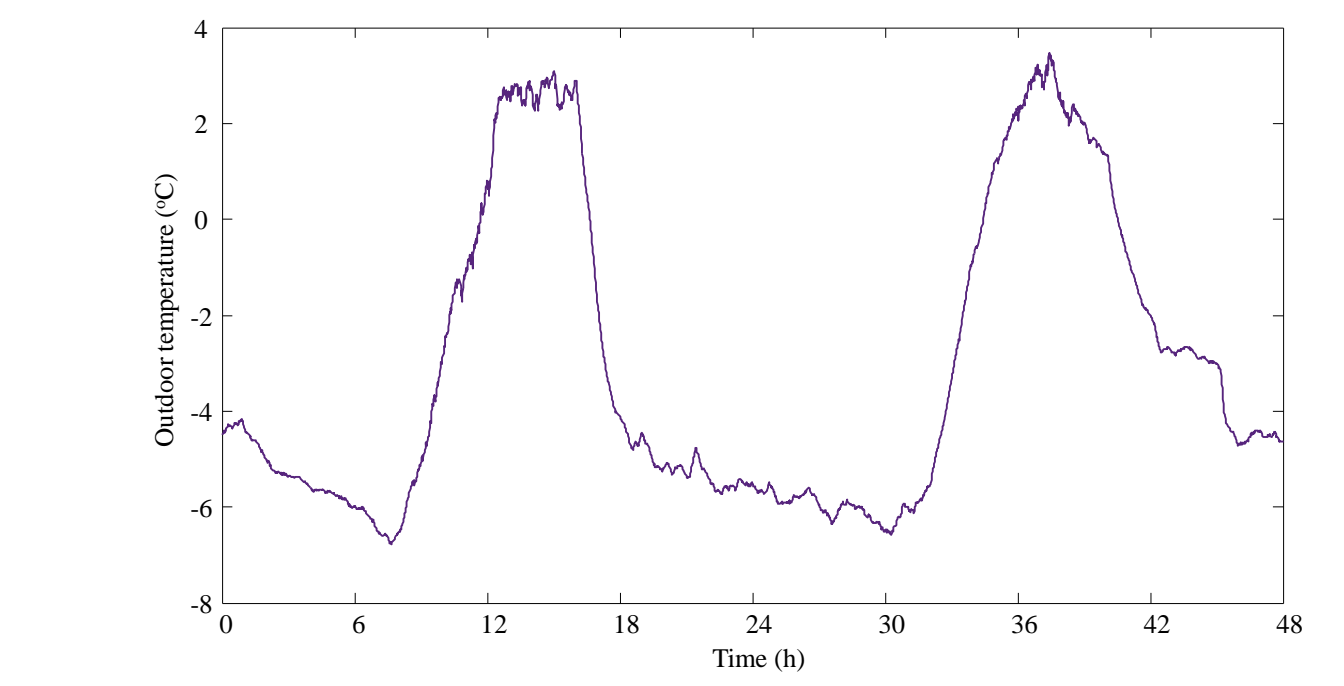

(b) .
176

177

178

179

180

181

(c)

Fig.4. Measured primary side data of a heating substation in Tianjin, China. (a) Measured primary side flow rate. (b) Measured primary supply temperature. (c) Measured outdoor temperature.

3. Modeling the plate heat exchanger 

partial differential equations (PDEs) [11]:

$$
\begin{aligned}
& \frac{\partial T_{h}}{\partial t}=\frac{q_{h}}{M b d} \frac{\partial T_{h}}{\partial x}+\frac{k}{\rho c_{p} d}\left(T_{l}-T_{h}\right) \\
& \frac{\partial T_{l}}{\partial t}=-\frac{q_{l}}{M b d} \frac{\partial T_{l}}{\partial x}+\frac{k}{\rho c_{p} d}\left(T_{h}-T_{l}\right)
\end{aligned}
$$

where $T_{h}$ and $T_{l}$ are the temperature distribution of the high temperature side and the low temperature side, respectively. $M$ is the number of flow channels in each side. $b$ is the width of each flow channel. $d$ is the distance between neighboring plates. $q_{h}$ and $q_{l}$ are the flow rates of the high temperature side and low temperature side, respectively. $\rho$ is the water density. $c_{p}$ is the specific thermal capacity. $k$ is the overall heat transfer coefficient of the plate heat exchanger, which is the function of flow rates of the two sides. Calculation of $k$ is summarized in Appendix A. model with the finite volume/difference method. Fig. 4 illustrates the finite volume division of the plate heat exchanger. The ODE model of plate heat exchanger can be derived as:

where $\Delta x=l / N ; j=1, \ldots, N ; l$ is the channel length; $N$ is the number of volumes divided in each channel; $T_{h, N+1}=T_{h, \text { in }}$ and $T_{l, 0}=T_{l, i n}$ are the inlet temperatures of the high temperature and low temperature sides, respectively; $T_{h, 1}=T_{h, \text { out }}$ and $T_{l, N}=T_{l, o u t}$ are the outlet temperatures of the high temperature and low temperature sides, respectively. 


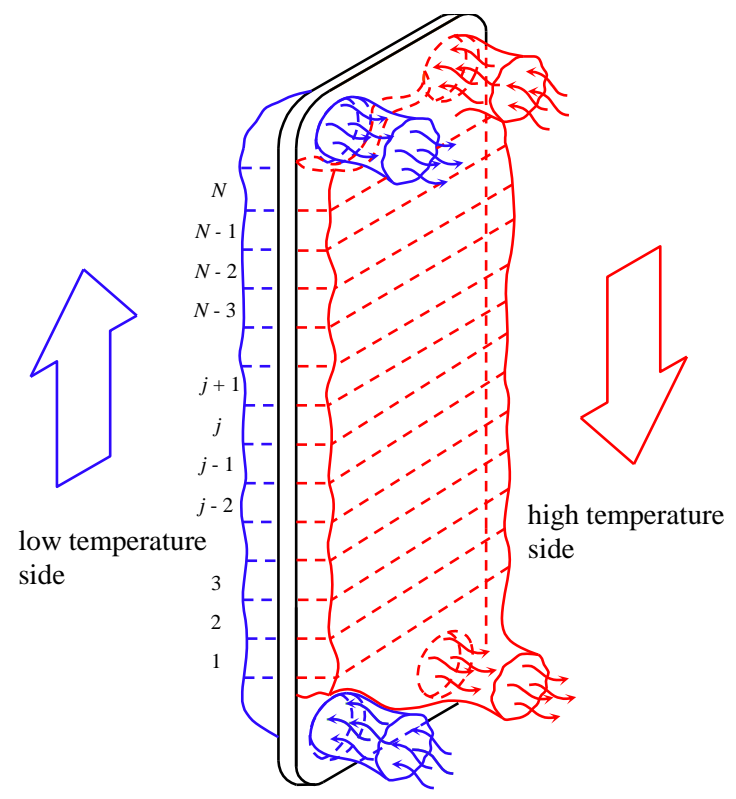

Fig. 4. Finite volume division of the plate heat exchanger flow channel.

The feedback control theory based method adopted in this paper generally includes three steps. The first step is to develop the dynamic model of plate heat exchanger, control valve and controller. The dynamic model of plate heat exchanger is a pair of nonlinear ordinary differential equations describing the thermal dynamics of the heat transfer process between the high temperature and low temperature sides. Since the models of plate heat exchanger and control valve are nonlinear, they should be linearized at an equilibrium point for stability analysis of the heating substation control loop with the feedback control theory. The second step is to do Laplace transform for the linearized models and derive the loop transfer function of the whole system $L(s)$ (transfer function from primary flow rate to secondary supply temperature) [12]. The third step is to draw the curve of $L(s)$ on the complex plane for $s$ varying along the imaginary axis from 0 to i $\infty$. This curve is called the 
Nyquist curve [12]. The operation stability of heating substation can be judged with the relation between the Nyquist curve and the point $(0,-1)$ on the complex plane. The Nyquist curve method for analyzing stability of dynamic systems named the Nyquist criterion was developed in 1930s, which has become a core concept and technique of classical control theory [12]. The Nyquist criterion is very applicable to practical problems and has been extended to more modern control technique [17].

The rest of this paper is organized as follows. The next section illustrates the control levels of the whole district heating system. The primary flow rate oscillation was observed from the measured data of a heating substation in Tianjin, China. Then the nonlinear ordinary differential equation model of plate heat exchanger was derived. The stability analysis method for heating substation was developed with the linearized model of heating substation and the Nyquist criterion. The nonlinear plate heat exchanger model was validated with measured data from the literature. The dynamic responses and operation stability of a heating substation were studied for application of the proposed stability analysis method.

\section{Operation stability analysis method}

\subsection{Model linearization}

Dynamic model of plate heat exchanger Eq. (5) and (6) is nonlinear. In order to analyze the operation stability with the frequency domain method, model linearization is required [17]. The nonlinear model described by Eq. (5) and (6) can be linearized into the following linear state space form: 


$$
T_{l, o u t}=C T
$$

where $T=\left[\begin{array}{llllllll}T_{h, 1} & T_{h, 2} & \cdots & T_{h, N} & T_{l, 1} & T_{l, 2} & \cdots & T_{l, N}\end{array}\right]^{\mathrm{T}} . A, B_{1}, B_{2}, B_{3}, B_{4}$ and $C$ are constant matrices (details for derivation of the matrices are listed in Appendix A). Doing Laplace transform to Eq. (7) and (8), the input-output model of plate heat exchanger can be written in the following form:

$$
T_{l, \text { out }}=G(s) q_{h}+G_{d, 1}(s) q_{l}+G_{d, 2}(s) T_{h, \text { in }}+G_{d, 3}(s) T_{l, \text { in }}
$$

where $G(s), G_{d, 1}(s), G_{d, 2}(s)$ and $G_{d, 3}(s)$ are transfer functions, that can be linearizing a nonlinear system like Eq. (5) and (6), an equilibrium point should be specified. The equilibrium point of Eq. (5) and (6) is the solution of the steady state Eq. (5) and (6) (of which the time derivatives are made zero), with specified steady state inputs: $q_{h}, q_{l}, T_{h, \text { in }}$ and $T_{l, i n}$. Therefore, with different steady state inputs, different equilibrium points can be derived. Since the matrices: $A, B_{1}, B_{2}, B_{3}$ and $B_{4}$ of the linearized model Eq. (7) and (8) are dependent on the equilibrium point.

Different selection of equilibrium points will lead to different linearized models.

However, all of the possible equilibrium points of the nonlinear system (Eq. (5) and (6)) lead to a set of linearized models, with which it is sufficient to study the robust stability of the nonlinear system [17].

The input-output structure of plate heat exchanger is illustrated in Fig. 5. The inputs can be divided into two categories: manipulated inputs and disturbance inputs. In district heating substation, the secondary supply temperature $T_{l, o}$ is controlled by 

primary supply temperature $T_{h, i n}$, secondary flow rate $q_{l}$ and secondary return temperature $T_{l, i n}$ are disturbance inputs .

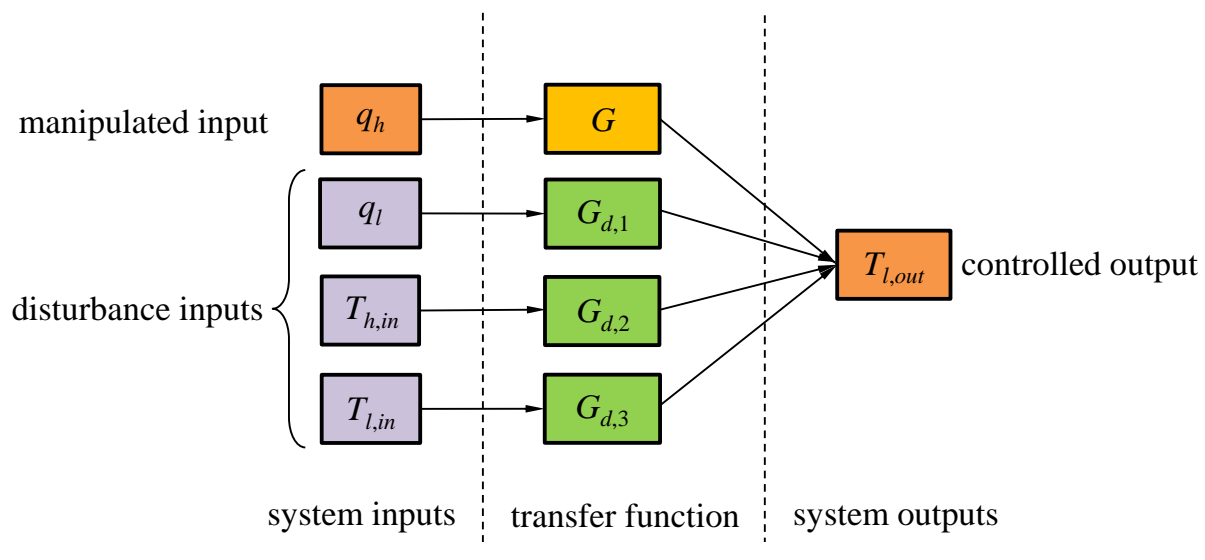

Fig. 5. Input-output structure of the plate heat exchanger.

\subsection{Models of the controller and valve}

The PI control law is usually adopted as feedback controller $K$ in district

272 heating substation, and $K$ can be represented as the Laplace transform form:

273

$$
K=k_{c} \frac{s+z}{s}
$$

274 where $k_{c}>0$ is the controller gain and $z>0$ is controller zero.

The equal percentage valve is usually used in heating substation. The characteristic for equal percentage valve is nonlinear. The relation between flow rate and valve opening of equal percentage valve can be characterized by the following formula $[13,18]$ :

$$
q=C_{\mathrm{v}} \sqrt{\Delta p} R^{x-1}
$$

280 where $C_{\mathrm{v}}$ is the flow capacity of the valve; $R$ is the rangeability of the valve; $\Delta p$ is the pressure difference of the valve. Fig. 6 shows the characteristic of an equal 
by:

$$
k_{v}=\left(\frac{\partial q}{\partial x}\right)_{x=x_{0}}
$$

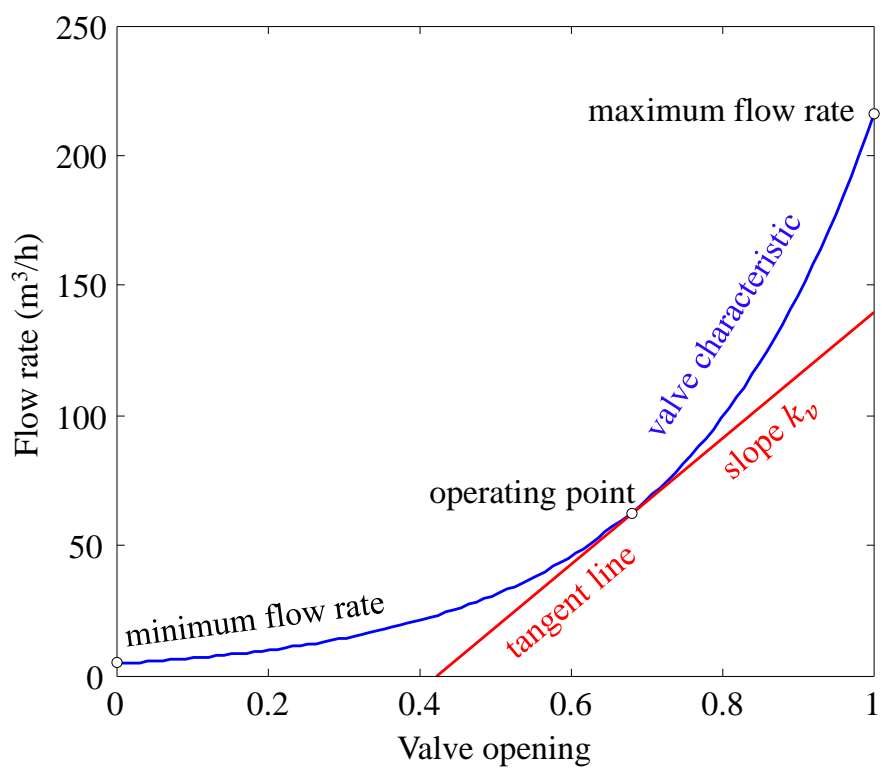

Fig. 6. Characteristic of an equal percentage valve.

292 illustrated as Fig. 7. Since the valve characteristic is nonlinear, the valve gain $k_{v}$ is 293 varying with the operating point $x_{0}$ changing. The varying range of valve gain $294 k_{v, \min } \leq k_{v} \leq k_{v, \max }$ can be derived from the valve characteristic Eq. (11) and (12) 295 as follows.

$$
k_{v, \min }=\left(\frac{\partial q}{\partial x}\right)_{x=0}=C_{\mathrm{v}} \sqrt{\Delta p} R^{-1} \ln R
$$




$$
k_{v, \max }=\left(\frac{\partial q}{\partial x}\right)_{x=1}=C_{\mathrm{v}} \sqrt{\Delta p} \ln R
$$

Therefore, the varying valve gain satisfies:

$$
C_{\mathrm{v}} \sqrt{\Delta p} R^{-1} \ln R<k_{v} \leq C_{\mathrm{v}} \sqrt{\Delta p} \ln R
$$

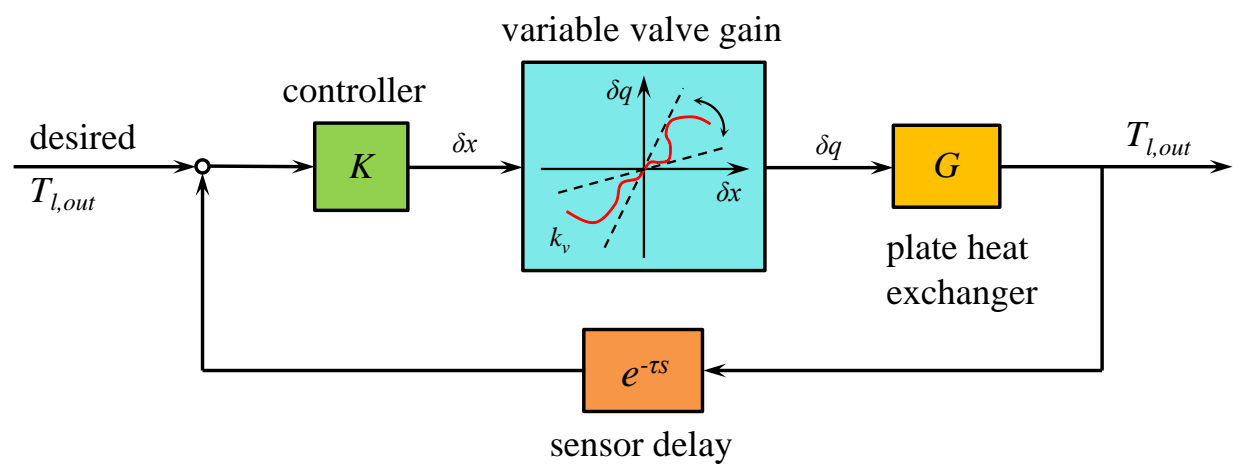

Fig. 7. Block diagram of heating substation control system.

\subsection{Stability criterion of heating substation}

According to the feedback control theory [17], the operation stability of feedback control system can be judged by the Nyquist stability criterion. If introducing this criterion to heating substation system, the operation stability of district heating substation can be judged by the following criterion:

If the curve of $L(s)=k_{v} K(s) G(s) e^{-\tau s}$ (s is varying along the imaginary axis from 0 to i $\infty$ ) encircles or crosses the point $(-1,0)$ on the complex plane, the heating substation control system will be unstable.

Here the complex variable $s$ can be replaced by the pure imaginary variable $\mathrm{i} \omega$ with $0 \leq \omega<+\infty$, where $\mathrm{i}=\sqrt{-1}$. Fig. 8 shows three cases of the relation between the curve of $L(\mathrm{i} \omega)$ and the point $(-1,0)$. For cases $(\mathrm{b})$ and (c), the heating substation 
will be unstable.

316

317

318

319

320

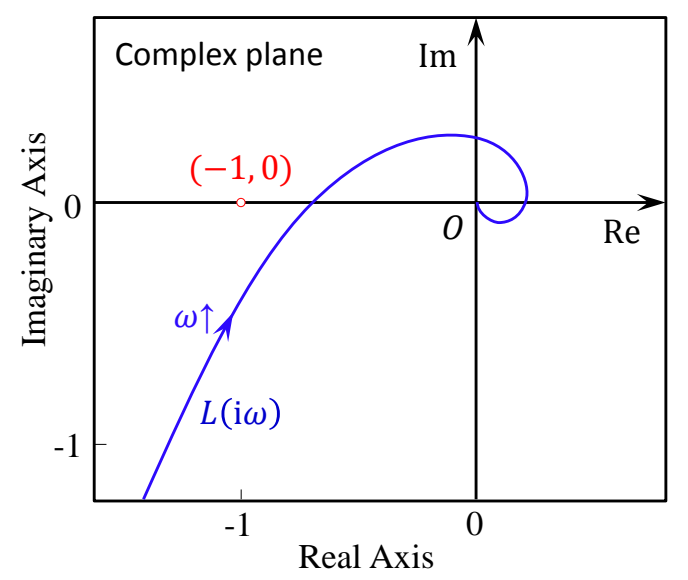

(a)

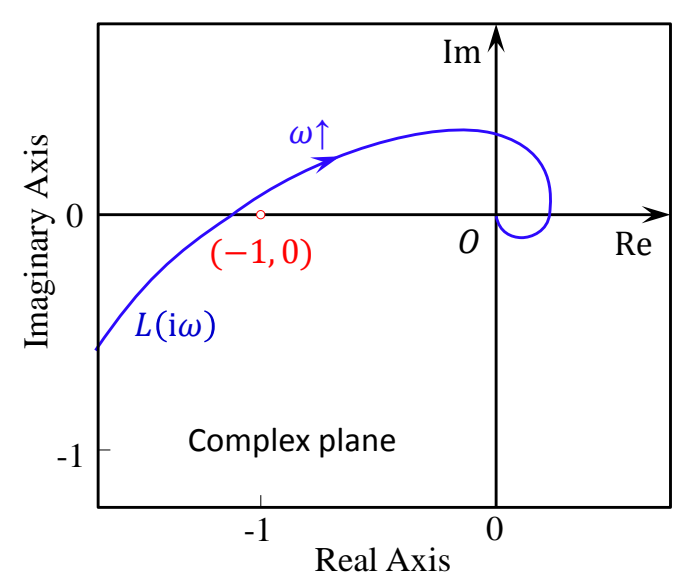

(b)

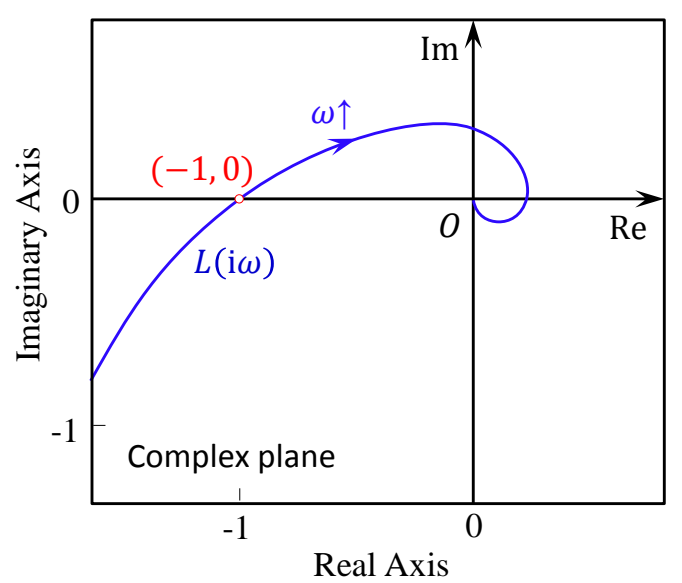


Fig. 8. Nyquist plots for operation stability analysis of heating substation. (a) The curve of $L(\mathrm{i} \omega)$

doesn't encircle point $(-1,0)$. (b) The curve of $L(\mathrm{i} \omega)$ encircles point $(-1,0)$. (c) The curve of

$L(\mathrm{i} \omega)$ crosses the point $(-1,0)$

Since the dynamics of plate heat exchanger is nonlinear, the linearized model $G$ will be perturbed to $G^{\prime}\left(G^{\prime} \neq G\right)$, if the operating condition (equilibrium point) is changed. And the perturbation may lead to instability of the heating substation control system. According to the proceeding criterion and Fig.8, operation stability of heating substation will be damaged, if the perturbed system $G^{\prime}$ causes the curve of $L^{\prime}(\mathrm{i} \omega)=$ $k_{v}{ }^{\prime} K(\mathrm{i} \omega) G^{\prime}(\mathrm{i} \omega) e^{-\mathrm{i} \omega \tau}$ to encircle or cross the point $(-1,0)$. The conversion from stability to instability may happen, when operating condition of plate heat exchanger in heating substation changes largely. As is observed in Fig. 3, with the primary which means that if the absolute value of $L(\mathrm{i} \omega)$ is small enough, operation stability 
the Nyquist plots of all possible operating conditions (equilibrium points). As is shown if all of these curves do not encircle or cross point $(-1,0)$, the heating substation will be stable at all operating conditions. This is equivalent to that the worst case Nyquist curve doesn't encircle or cross point $(-1,0)$.

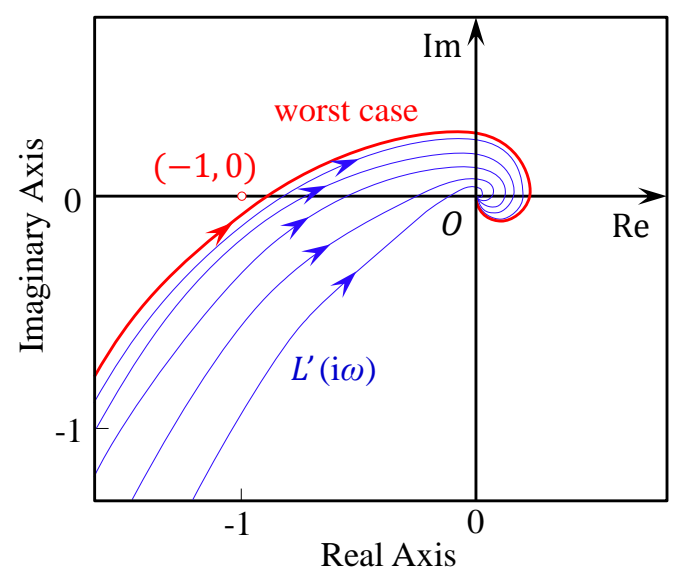

Fig. 9. Nyquist plots of all possible operating conditions (equilibrium points).

With this criterion, the operation stability of heating substation is predictable. Besides, for an unstable operation condition of heating substation, this criterion can also be used to analyze the key factor which leads to the instability of the heating substation and tune the controller to ensure robust stability.

\section{Results and discussion}

\subsection{Validation of the nonlinear model}

The nonlinear model of plate heat exchanger described by Eq. (5) and (6) was established in Simulink (Fig. 10). In Ref. [16], Michel and Kugi have tested the 
dynamic operation of plate heat exchanger, and the measured data were used to

362 validate the dynamic model of plate heat exchanger. If the nonlinear model of plate

363 heat exchanger described by Eq. (5) and (6) is effective, the model should be able to

364 predict the dynamic operation in Ref. [16]. The plate heat exchanger parameters and

365 measured data including the boundary conditions of inlet temperatures and flow rates

366 in both sides given in Ref. [16] have been used to validate the proposed nonlinear

367 model described by Eq. (5) and (6). The nonlinear model was validated using the

368 measured data and plate heat exchanger parameters given in Ref. [16]. The simulated

369 and measured outlet temperatures $T_{h, o u t}$ and $T_{l, o u t}$ are shown in Fig. 11, and the

370 relative errors of $T_{h, \text { out }}$ and $T_{l, \text { out }}$ are shown in Fig.12. Relative errors of the

371 simulated $T_{h, \text { out }}$ and $T_{l, \text { out }}$ are both varying within $\pm 8 \%$, which is in a satisfied

372 range. Therefore, the nonlinear model of the plate heat exchanger Eq. (5) and (6) can

373 describe the thermal dynamics of the plate heat exchanger with satisfied accuracy. 


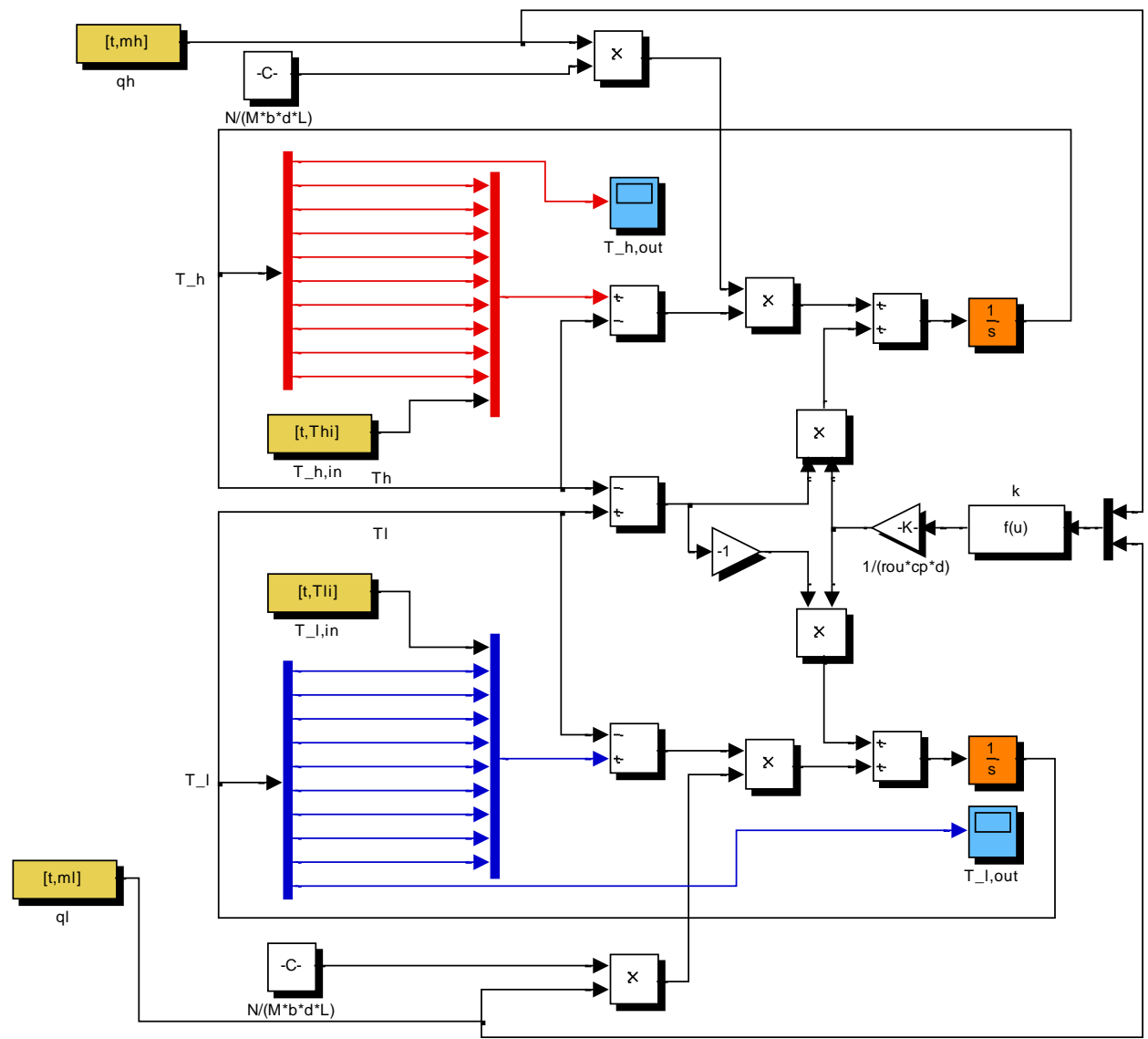

Fig. 10. Simulink model of the nonlinear plate heat exchanger model Eq. (5) and (6).

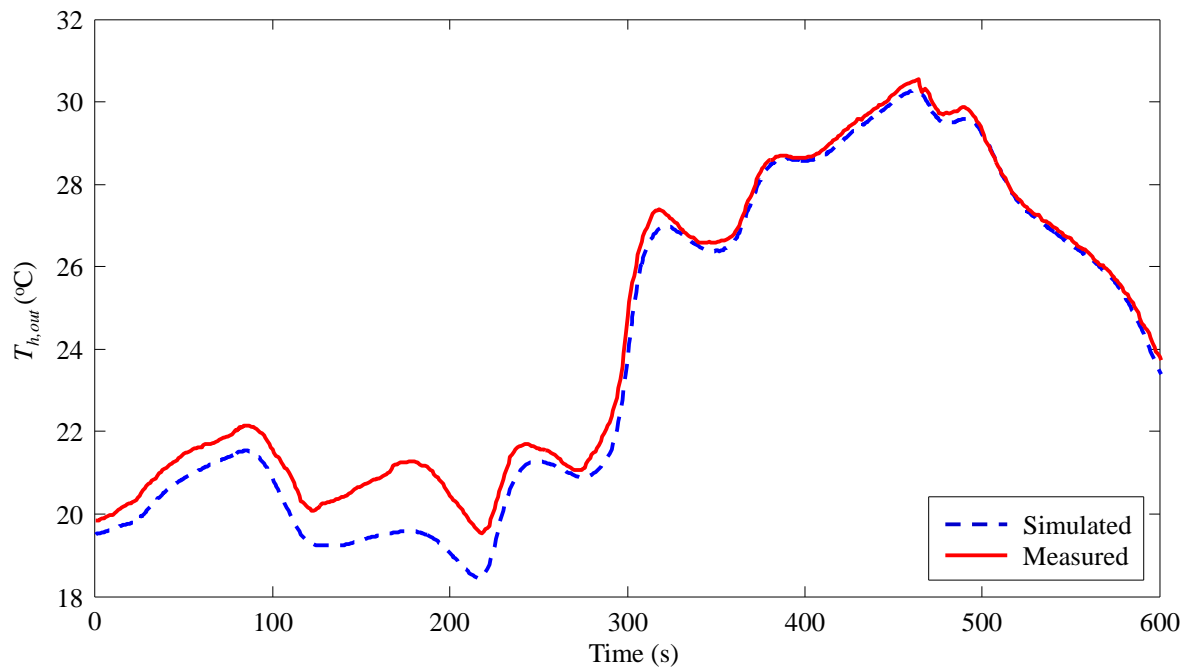




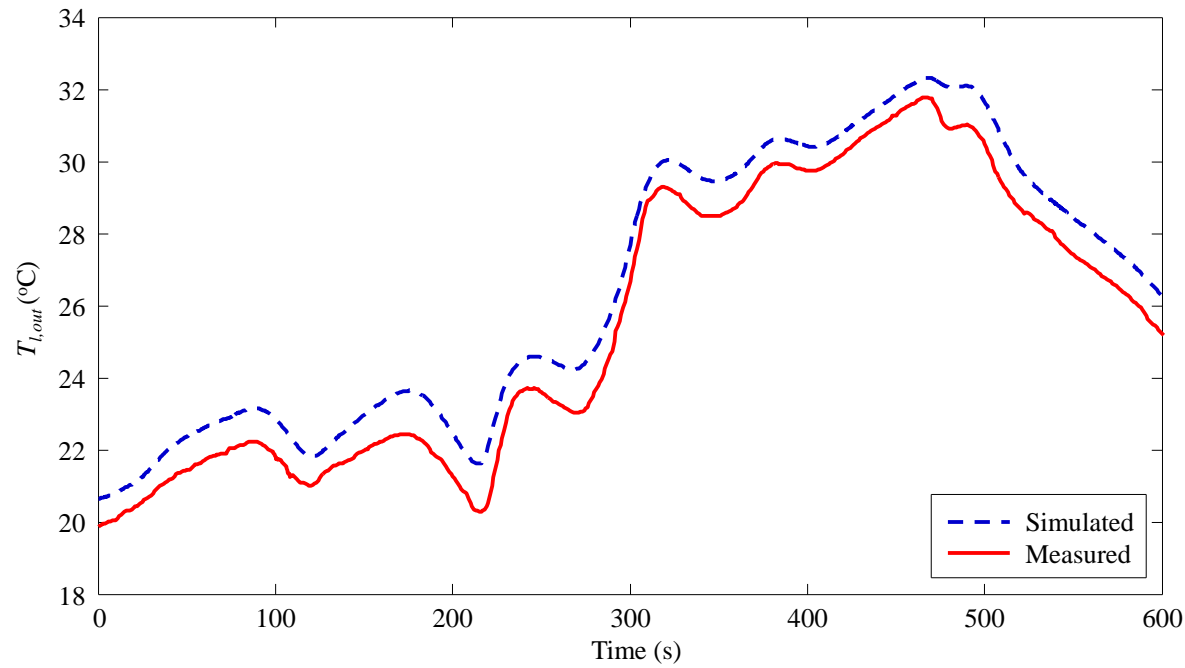

379

380

(b)

381

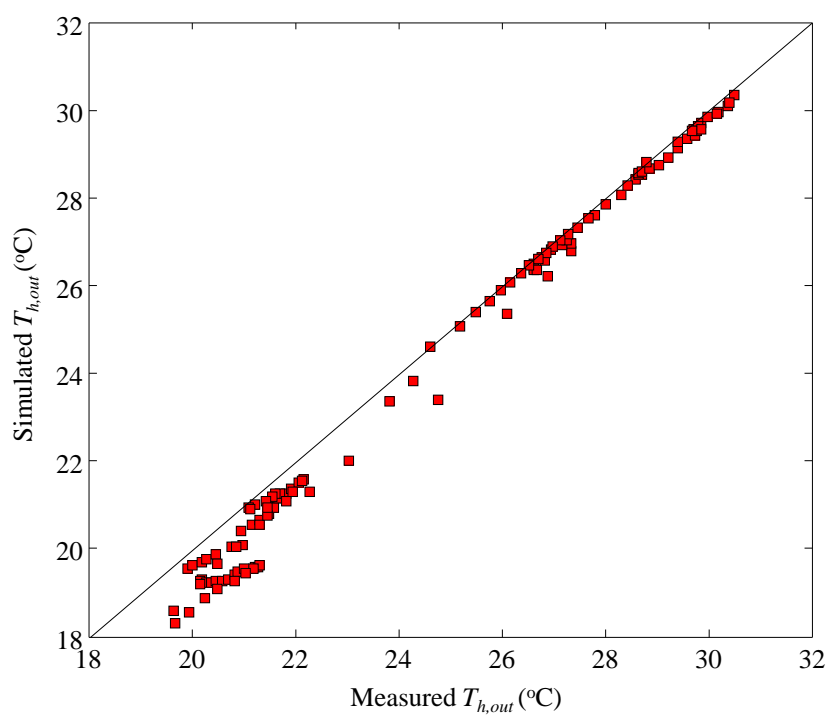

382

383

(c)

384 


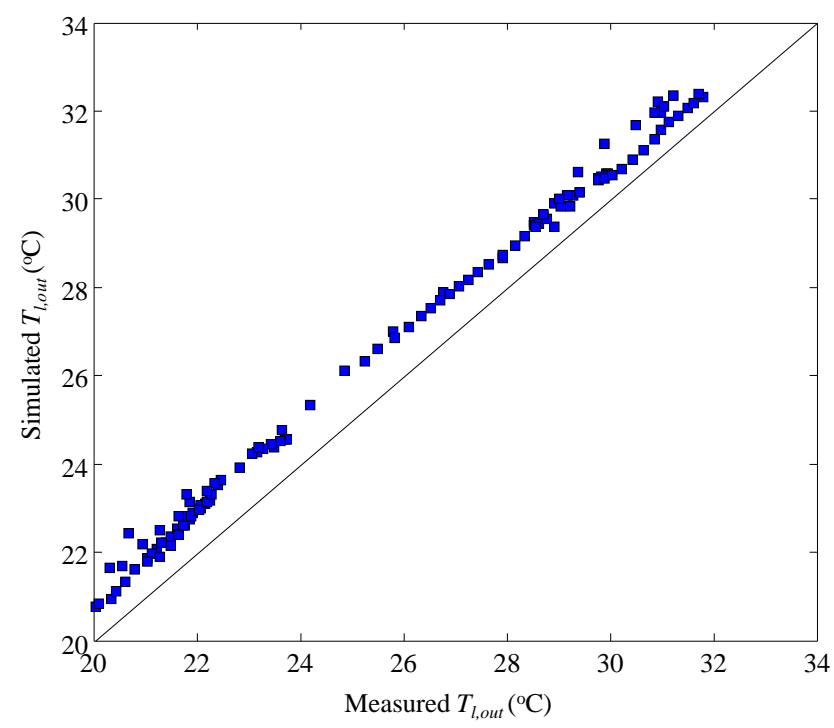

385

387 Fig. 11. Comparison of the measured and simulated outlet temperatures using parameters and

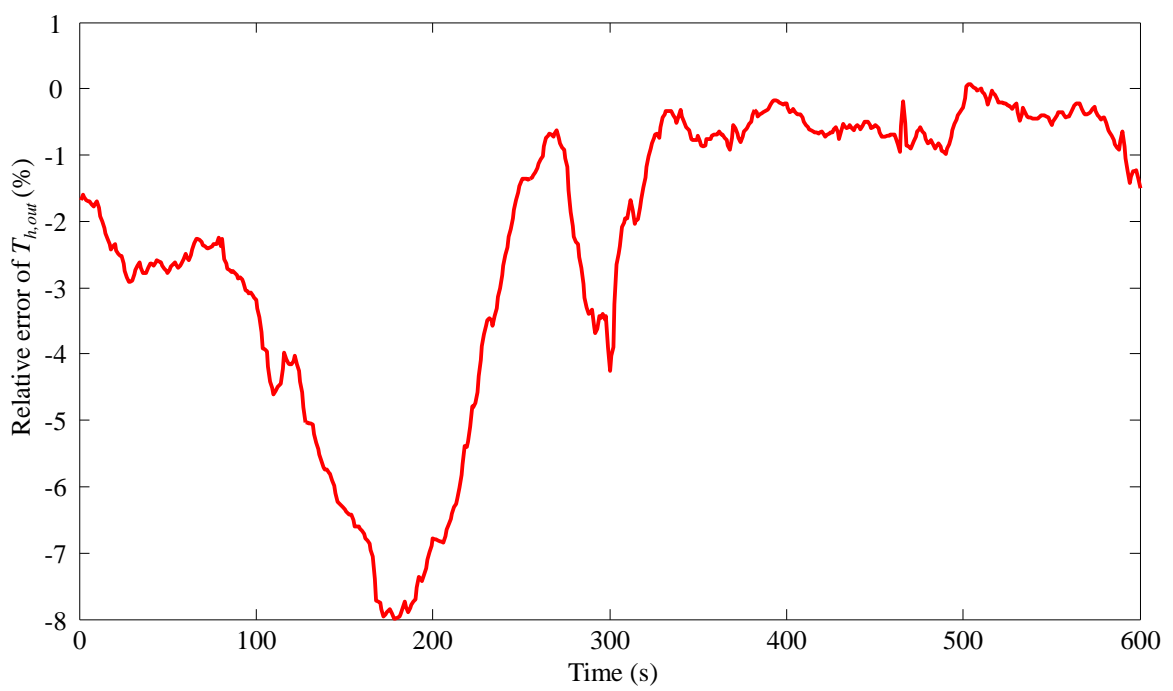




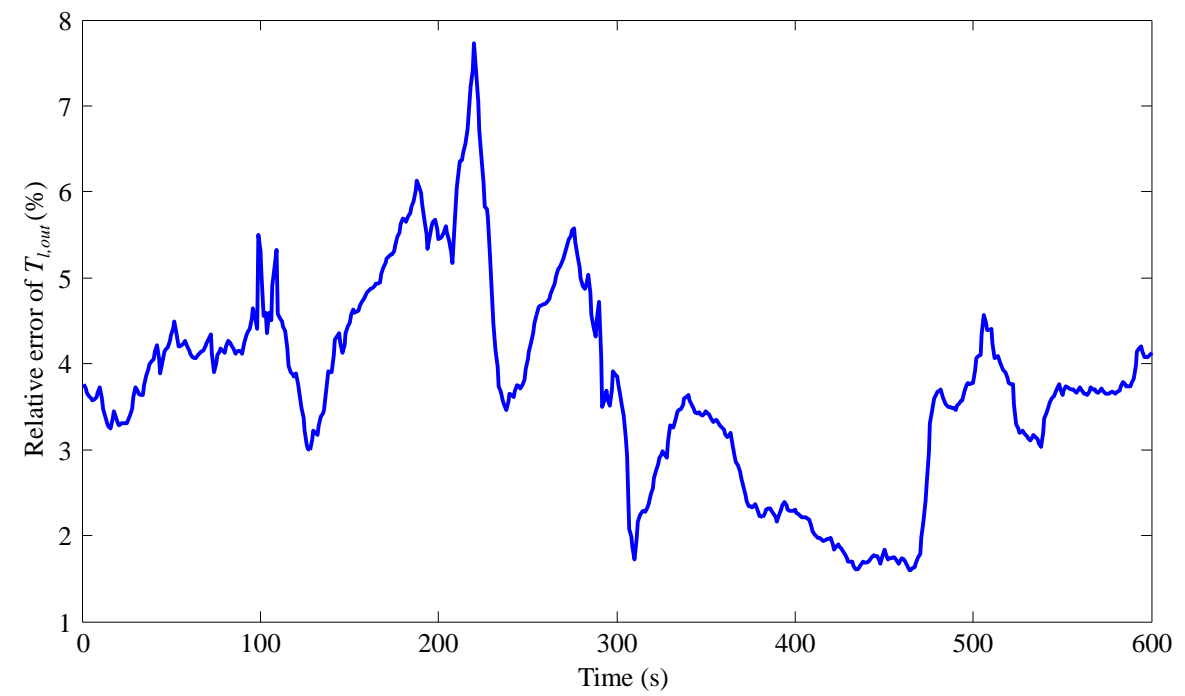

393

(b)

Fig. 12. Relative errors of the nonlinear model Eq. (5) and (6). (a) Relative error of $T_{h, o u t}$. (b)

Relative error of $T_{l, o u t}$.

The nonlinear heating substation control system composed of plate heat

\begin{tabular}{llll}
\hline Description & Symbol & Value & Unit \\
\hline channel width & $b$ & 0.8 & $\mathrm{~m}$ \\
channel length & $l$ & 1.36 & $\mathrm{~m}$ \\
\hline
\end{tabular}




\begin{tabular}{llll}
\hline water specific heat capacity & $c_{p}$ & 4220 & $\mathrm{~kJ} /(\mathrm{kg} \cdot \mathrm{K})$ \\
empirical parameters & $C$ & 0.64 & $/$ \\
distance between neighboring plates & $d$ & 4.5 & $\mathrm{~mm}$ \\
plate thickness & $d_{p}$ & 0.5 & $\mathrm{~mm}$ \\
number of flow channels in each side & $M$ & 137 & $/$ \\
empirical parameters & $n_{1}$ & 0.23 & $/$ \\
empirical parameters & $n_{1}$ & 0.75 & $/$ \\
water density & $\rho$ & 970 & $\mathrm{~kg} / \mathrm{m}{ }^{3}$ \\
thermal conductivity of high temperature side water & $\lambda_{h}$ & 0.68 & $\mathrm{~W} /(\mathrm{m} \mathrm{K})$ \\
thermal conductivity of low temperature side water & $\lambda_{l}$ & 0.67 & $\mathrm{~W} /(\mathrm{m} \mathrm{K})$ \\
thermal conductivity of plate & $\lambda_{p}$ & 15 & $\mathrm{~W} /(\mathrm{m} \cdot \mathrm{K})$ \\
dynamic viscosity of high temperature side water & $\mu_{h}$ & 0.00028 & $\mathrm{~Pa} \cdot \mathrm{m}$ \\
dynamic viscosity of low temperature side water & $\mu_{l}$ & 0.00041 & $\mathrm{~Pa} \cdot \mathrm{m}$ \\
\hline
\end{tabular}

Table 1. Parameters of plate heat exchanger

In this section, the operation stability of heating substation was studied. The controller was tuned with the frequency domain approach [12]. In order to illustrate that if the controller is tuned and works well under low primary supply temperature condition, the operation stability may not be ensured at high primary supply temperature, dynamic performances of heating substation under low and high primary supply temperatures with the PI controller tuned at low supply temperature were studied.

\subsubsection{Dynamic responses in low primary supply temperature}

The PI controller is usually tuned under a certain operating condition. For the case study in this subsection, the following low primary supply temperature operating 
$\mathrm{m}^{3} / \mathrm{s}$. The PI controller is tuned by simulating the reference tracking response of $T_{l, o u t}$ around the operating condition. The PI controller is tuned as:

$$
K_{1}=0.004 \frac{s+1}{s}
$$

421 The dynamic responses of heating substation control system were calculated with the

422

423

424

425

426

427 deviation of $T_{l, o u t}$ from desired value is within $2{ }^{\circ} \mathrm{C}$.

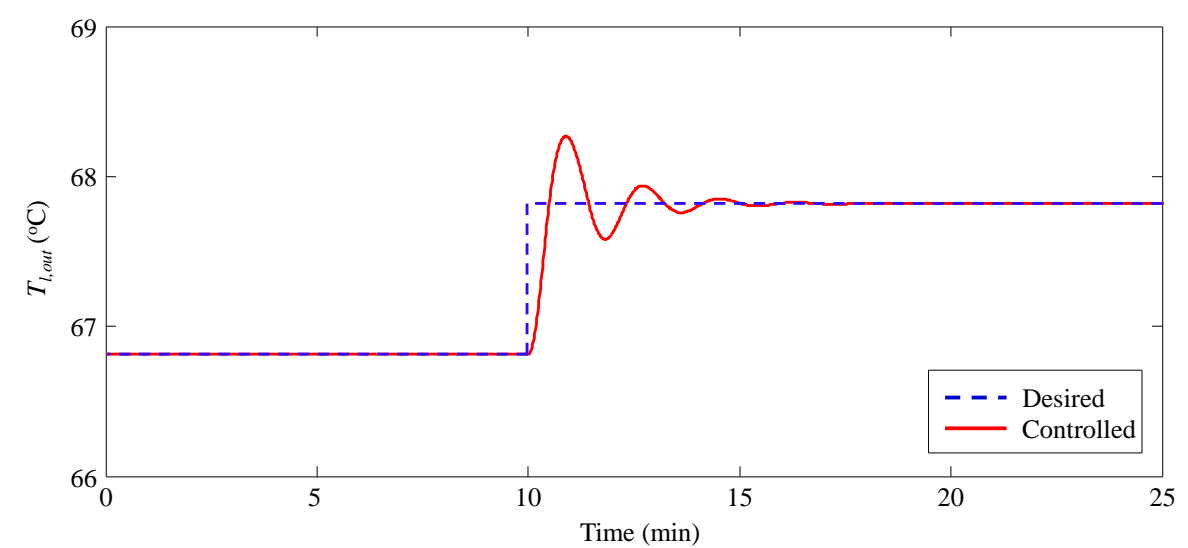

Fig. 13 shows the reference tracking responses under the control of $K_{1}$. When the desired secondary supply temperature $T_{l, \text { out }}$ changes from $66.8{ }^{\circ} \mathrm{C}$ to $67.8{ }^{\circ} \mathrm{C}$, the controlled $T_{l, \text { out }}$ tracks the new value in about 5 minutes and the overshoot is less than $0.5^{\circ}$ C. Fig. 14, Fig. 15 and Fig. 16 show the disturbance rejection responses to step variations of $T_{h, \text { in }}, T_{l, i n}$ and $q_{l}$, respectively. Fig. 14 shows that when primary supply temperature $T_{h, i n}$ changes from $70{ }^{\circ} \mathrm{C}$ to $71{ }^{\circ} \mathrm{C}$, the deviation of secondary supply temperature $T_{l, o u t}$ from the desired value can be controlled within $1{ }^{\circ} \mathrm{C}$. Fig. 15 shows that if secondary return temperature changes from $40{ }^{\circ} \mathrm{C}$ to $35^{\circ} \mathrm{C}$, the deviation of $T_{l, o u t}$ from desired value can be restricted within $0.5{ }^{\circ} \mathrm{C}$. Fig. 16 shows that when the secondary flow rate $q_{l}$ varies from $0.03 \mathrm{~m}^{3} / \mathrm{s}$ to $0.04 \mathrm{~m}^{3} / \mathrm{s}$, the 


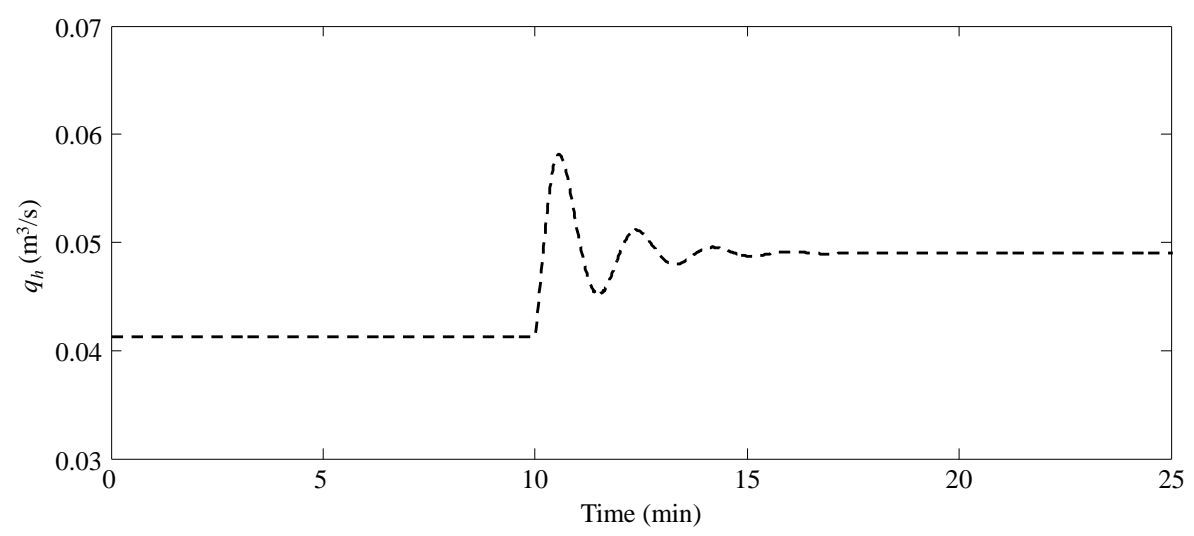

436

437

438

439

440

441

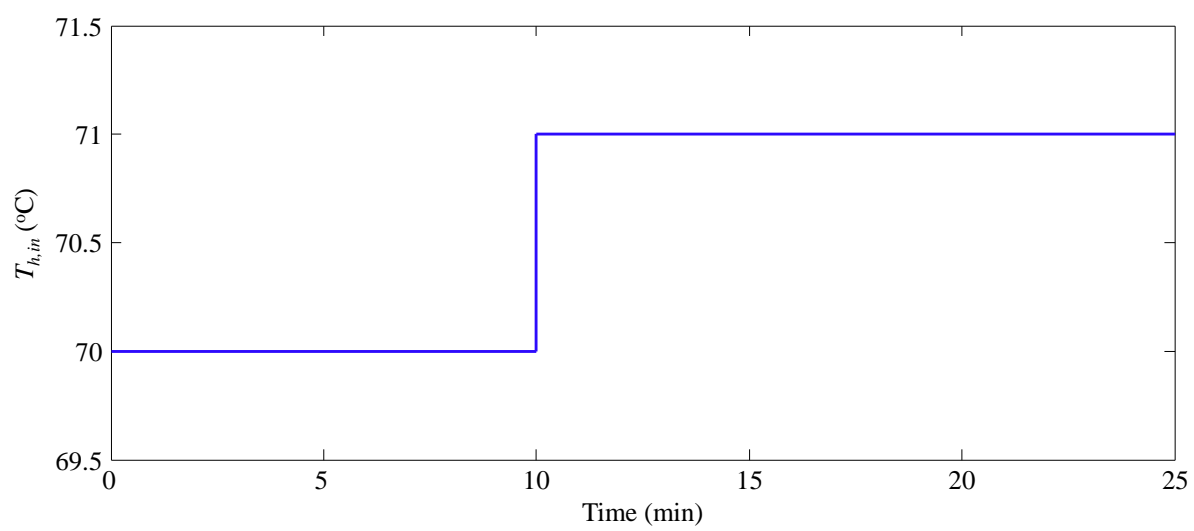

Fig. 13. System responses for tracking desired $T_{l, o}$ under the control of controller $K_{1}$ (with $T_{l, \text { in }}=40{ }^{\circ} \mathrm{C}, T_{h, \text { in }}=70{ }^{\circ} \mathrm{C}, q_{l}=0.03 \mathrm{~m}^{3} / \mathrm{s}$.). (a) Tracking response of $T_{l, o}$. (b) Tracking response of $q_{h}$. 

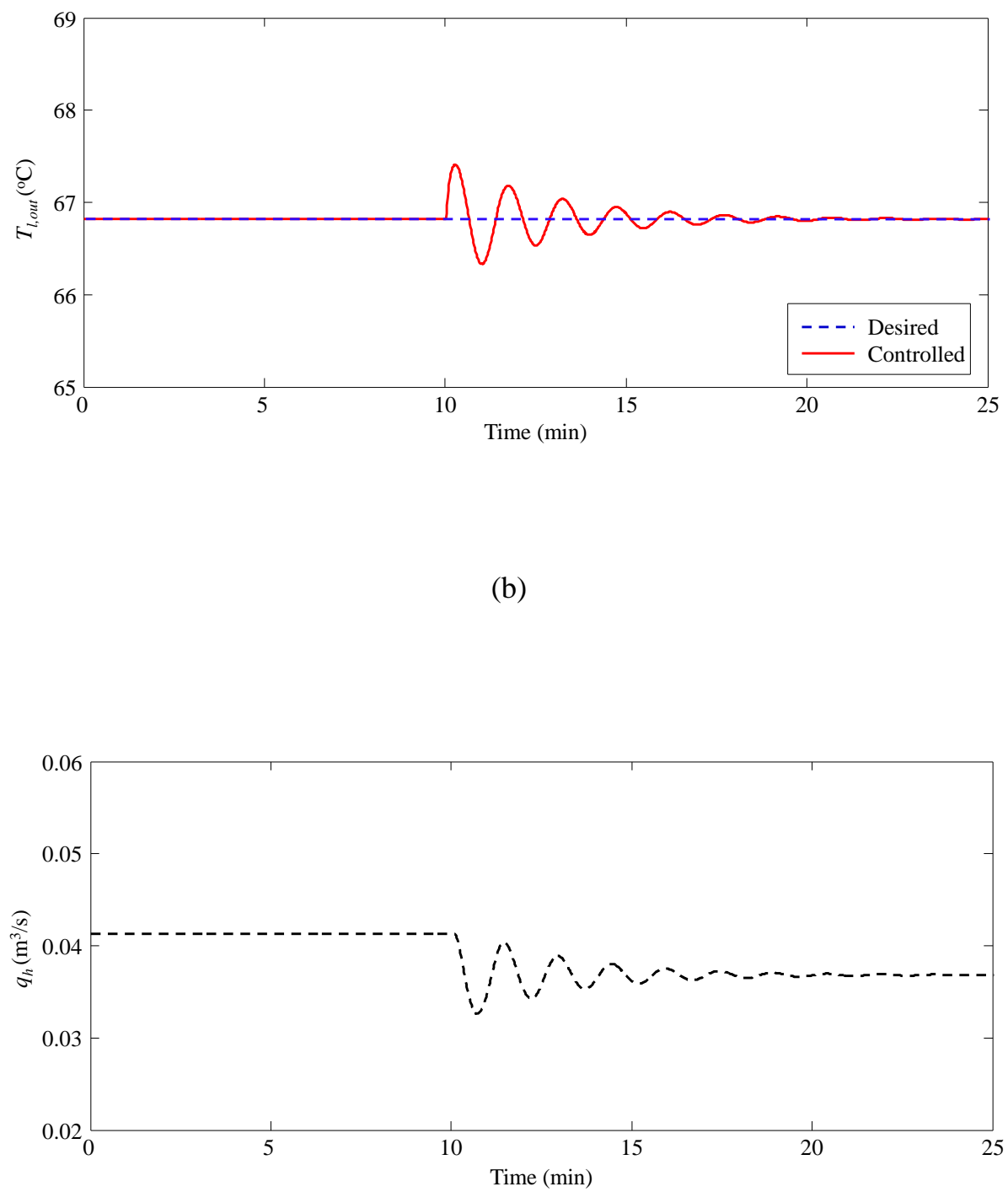

447

449 Fig. 14. System responses for rejecting the variation of $T_{h, i n}$ under the control of $K_{1}$ (with

451 Response of controlled $T_{l, \text { out }}$. (c) Response of $q_{h}$. 


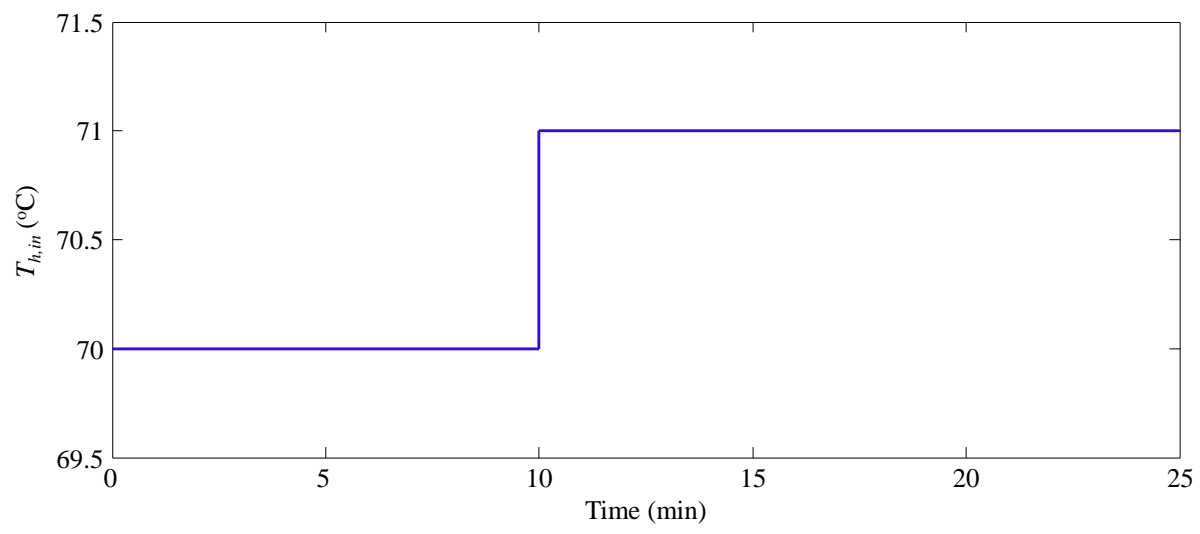

453

454

(a)

455

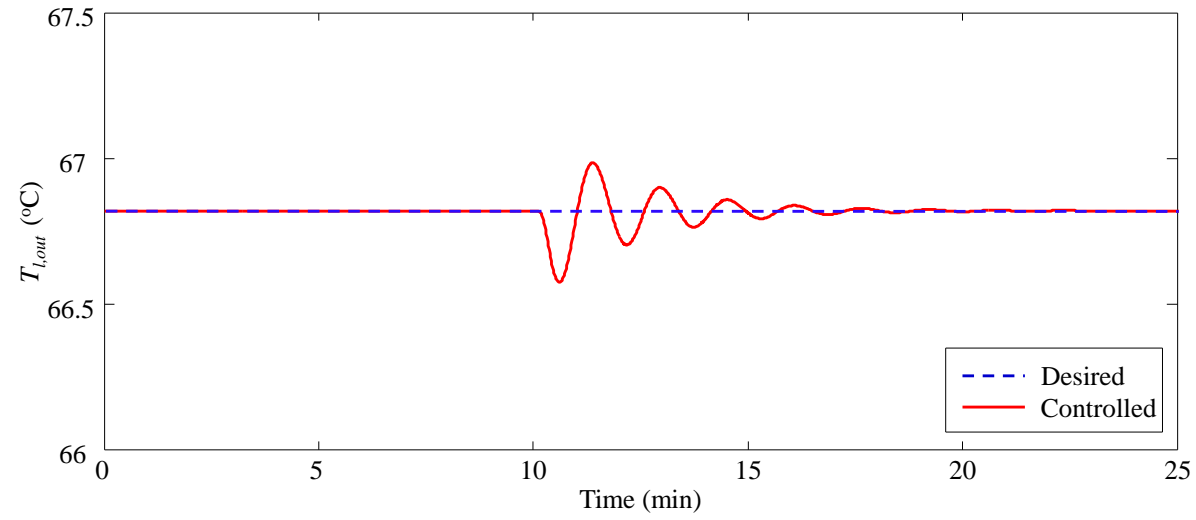

456

457

(b)

458 


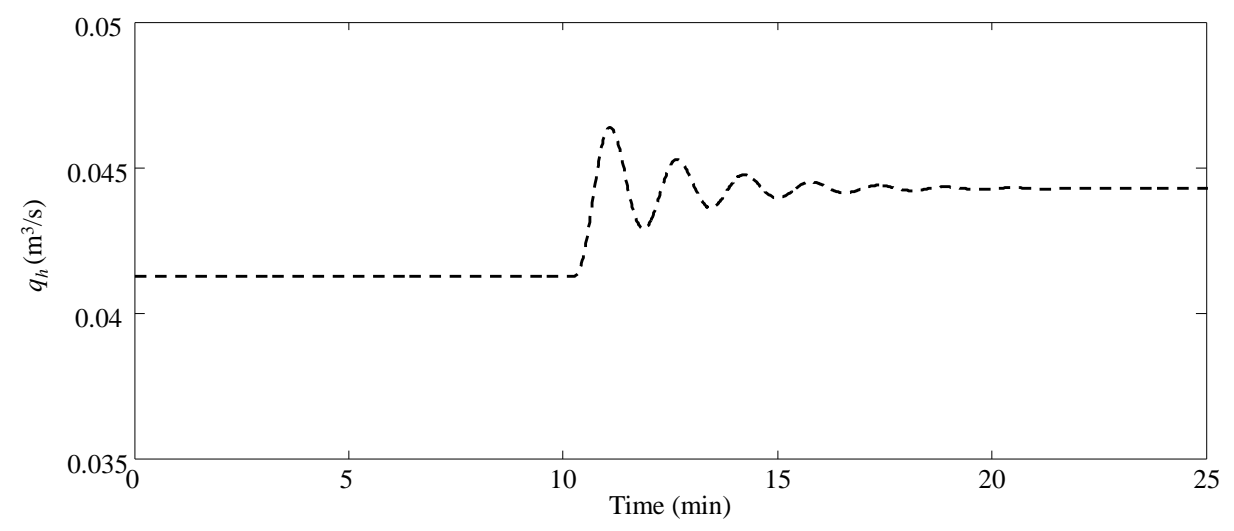

459

461 Fig. 15. System responses for rejecting the variation of $T_{l, i n}$ under the control of $K_{1}$ (with 462 $T_{h, \text { in }}=70{ }^{\circ} \mathrm{C}, q_{l}=0.03 \mathrm{~m}^{3} / \mathrm{s}$ and the desired $T_{l, o u t}=66.8^{\circ} \mathrm{C}$ ). (a) Variation of $T_{l, i n}$. (b)

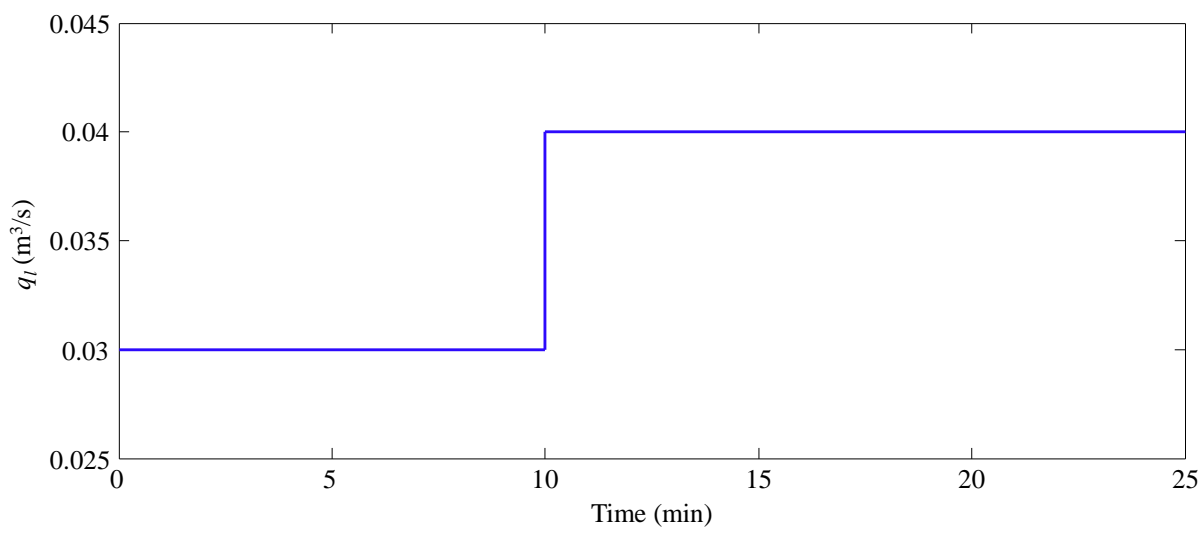



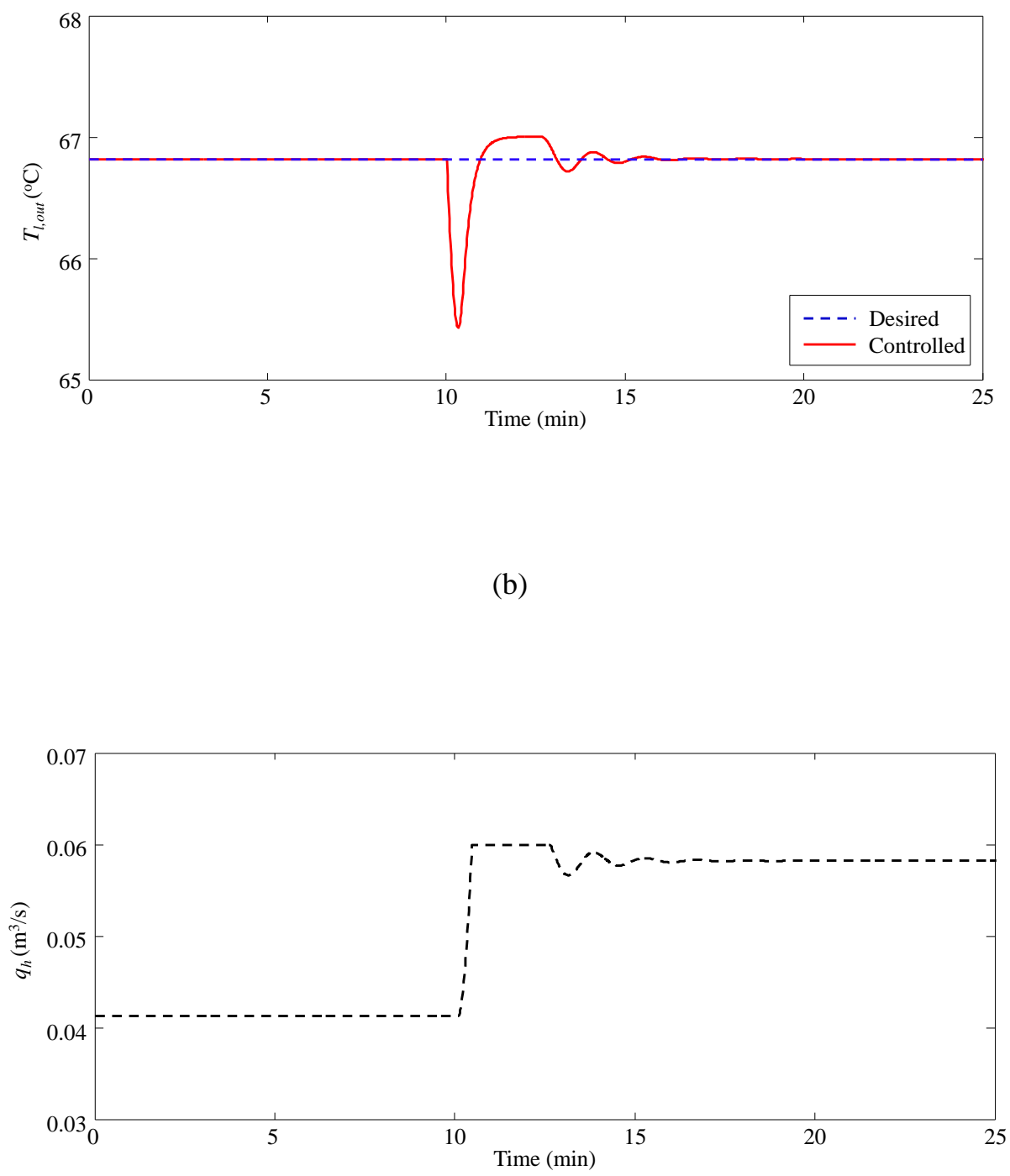

473 Fig. 16. System responses for rejecting the variation of $q_{l}$ under the control of $K_{1}$ (with $T_{h, i n}=$ $47470{ }^{\circ} \mathrm{C}, T_{l, \text { in }}=40{ }^{\circ} \mathrm{C}$ and desired $T_{l, o u t}=66.8^{\circ} \mathrm{C}$ ). (a) Variation of $q_{l}$. (b) Response of controlled $T_{l, o u t}$. (c) Response of $q_{h}$. These reference tracking and disturbance rejection responses indicate that under 477 the control of $K_{1}$, the heating substation system is stable around the operating 478 condition of $T_{h, i n}=70{ }^{\circ} \mathrm{C}, T_{l, i n}=40{ }^{\circ} \mathrm{C}, q_{l}=0.03 \mathrm{~m}^{3} / \mathrm{s}$. Hence, the tuned PI 479 controller $K_{1}$ seems to be suitable for the control of the heating substation with the 
480

481

482

483

484

485

486

487

488

489

490

491

492

493

494

495

496

497

498

499

500

501

proposed parameters. However, the simulation test of responses is only conducted around the operating condition of $T_{h, i n}=70{ }^{\circ} \mathrm{C}, T_{l, i n}=40{ }^{\circ} \mathrm{C}, q_{l}=0.03 \mathrm{~m}^{3} / \mathrm{s}$. When the operating condition changes largely, instability may occur as the measured data shown in Fig. 3.

\subsubsection{Robust stability test and retuning of the controller}

In order to investigate the stability of the heating substation under the control of controller $K_{1}$, the stability criterion proposed in subsection 4.3 was adopted. Fig. 17-(a) shows the Nyquist curves of the heating substation under the control of $K_{1}$ at all possible operating conditions. The possible operating conditions were defined as conditions that satisfy: $65{ }^{\circ} \mathrm{C} \leq T_{h, \text { in }} \leq 95{ }^{\circ} \mathrm{C}, 30{ }^{\circ} \mathrm{C} \leq T_{l, \text { in }} \leq 50{ }^{\circ} \mathrm{C}, 0.01 \mathrm{~m}^{3} / \mathrm{s} \leq$ $q_{h} \leq 0.06 \mathrm{~m}^{3} / \mathrm{s}$ and $0.03 \mathrm{~m}^{3} / \mathrm{s} \leq q_{h} \leq 0.04 \mathrm{~m}^{3} / \mathrm{s}$. This range can cover most of the operation conditions of the heating substation proposed in this paper. The proposed method in section 4.3 can be used to study the operation stability at these possible operating condition.

As is shown, the black curve, which denotes the Nyquist curve of the $T_{h, i n}=70$ ${ }^{\circ} \mathrm{C}, T_{l, \text { in }}=40{ }^{\circ} \mathrm{C}, q_{l}=0.03 \mathrm{~m}^{3} / \mathrm{s}$ condition, does not encircle or cross the point $(-1$, 0 ). This is the reason that the heating substation operates stably under the control of $K_{1}$ around the condition of $T_{h, i n}=70{ }^{\circ} \mathrm{C}, T_{l, i n}=40{ }^{\circ} \mathrm{C}, q_{l}=0.03 \mathrm{~m}^{3} / \mathrm{s}$. However, there are still many cases don't satisfy this criterion. This means that the heating substation will be unstable under the control of $K_{1}$ in some operating conditions. Fig. 18-(a) shows the variation of $T_{h, \text { in }}$ and desired $T_{l, o u t}$, which will lead to instability 
502

503

504

505

506

507

508

509

510

511

512

513

514

515

516

517

518

519

520

521

522

523

of the heating substation (with $T_{l, i n}=40{ }^{\circ} \mathrm{C}, q_{l}=0.03 \mathrm{~m}^{3} / \mathrm{s}$ ). As is shown in Fig. 18-(b) and 18-(c), the dynamic responses of $T_{l, o u t}$ and $q_{h}$ under the control of $K_{1}$ (drawn in dark blue) become oscillatory when the primary supply temperature $T_{h, i n}$ increases from $70{ }^{\circ} \mathrm{C}$ to $85{ }^{\circ} \mathrm{C}$. The oscillation form of the primary flow rate $q_{h}$, shown in Fig. 18-(b), is very similar to the measured primary flow rate data shown in Fig. 3-(a). The heating substation becomes unstable because the increase of primary supply temperature $T_{h, \text { in }}$ makes the loop gain $|L(\mathrm{i} \omega)|$ larger and causes the curve of $L(\mathrm{i} \omega)$ to encircle point $(-1,0)$. This phenomenon also indicates that the high primary supply temperature conditions are worse than low supply temperature conditions. This also demonstrates that controllers tuned at a certain operating condition cannot ensure stability for all operating conditions.

In order to stabilize the heating substation, controller $K_{1}$ should be tuned again by considering all the possible operating conditions. The red Nyquist curve in Fig. 17-(a) denotes the worst operation condition. If the worst condition Nyquist curve doesn't encircle or cross the point $(-1,0)$, the heating substation will be stable at all operating condition. Therefore, according to Fig. 17-(a), to make the red curve do not encircle or cross the point $(-1,0)$, the controller gain $k_{c}$ should be smaller. Fig. 17-(b) shows the Nyquist curves of the heating substation under the control of $K_{2}$ at all possible operating conditions, where

$$
K_{2}=0.002 \frac{s+1}{s}
$$

As is shown in Fig. 17-(b), the Nyquist curves of all the possible conditions do not 
524

525

526

527

528

529

530

531

532

533

534 conditions. very high.

encircle or cross the point $(-1,0)$. Therefore the heating substation under the control of controller $K_{2}$ will be stable even in worse condition. In Fig. 18-(b) and Fig. 18-(c), the responses drawn in red are under the control of $K_{2}$. As is shown, the operation of heating substation remains stable even when primary supply temperature increases to

Hence, the heating substation controller tuned at certain operating conditions may be unstable when operating condition changes in large range. To ensure operation stability of heating substation at all conditions, the operation stability should be tested when operating condition changes, and the proposed method can be used as a tool for analyzing the operation stability of heating substation at all possible operating analyzing the operation stability of heating substation at all possible operating

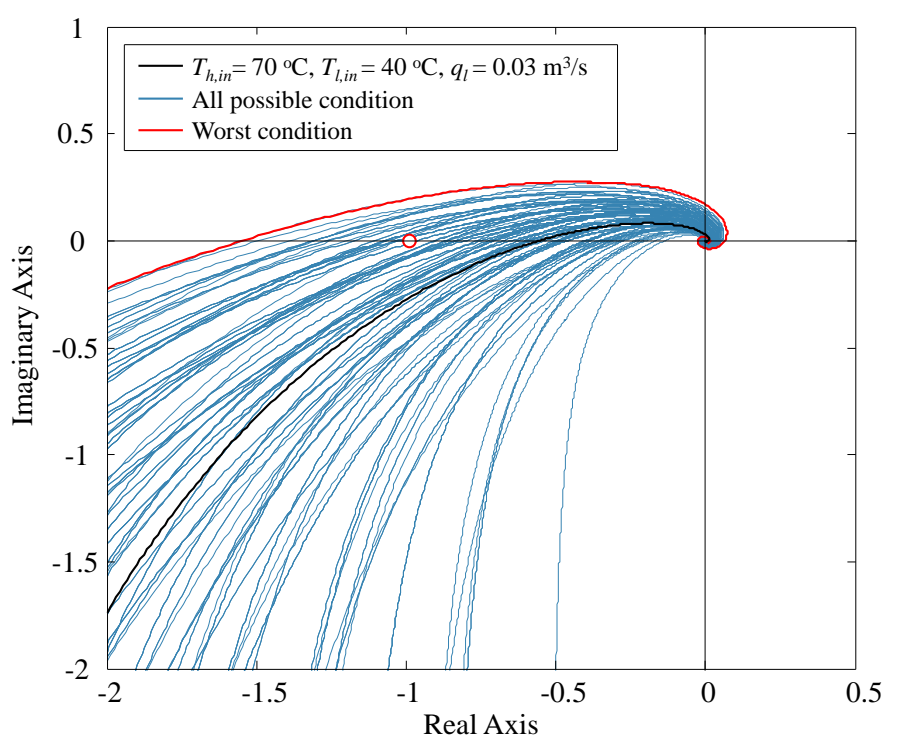




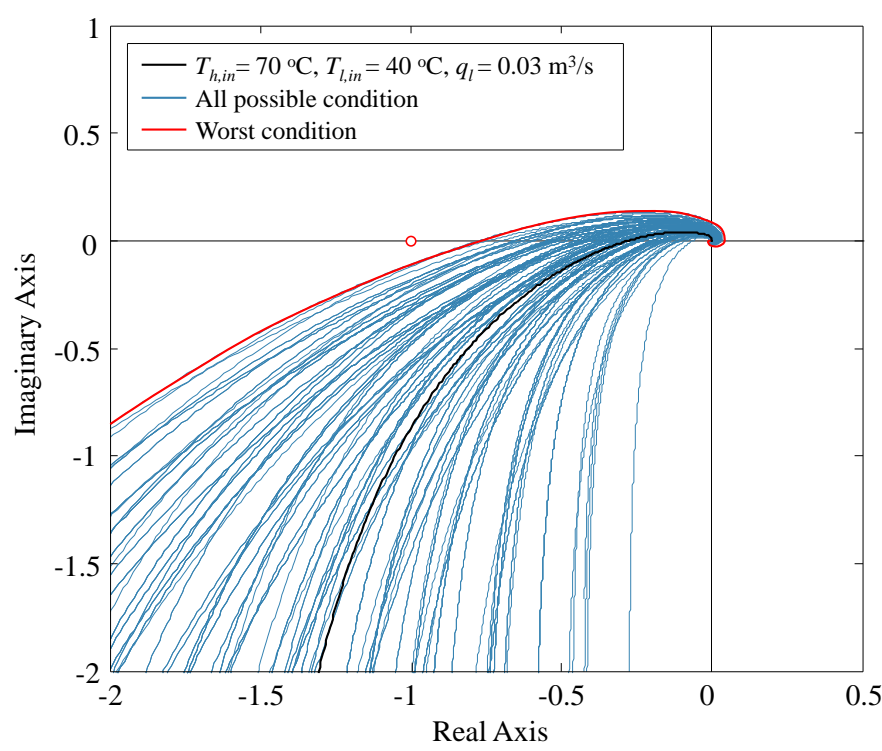

537

539 Fig. 17. Nyquist curves of heating substation system at all possible operating conditions. (a) Under

540 the control of $K_{1}$. (b) Under the control of $K_{2}$.

541

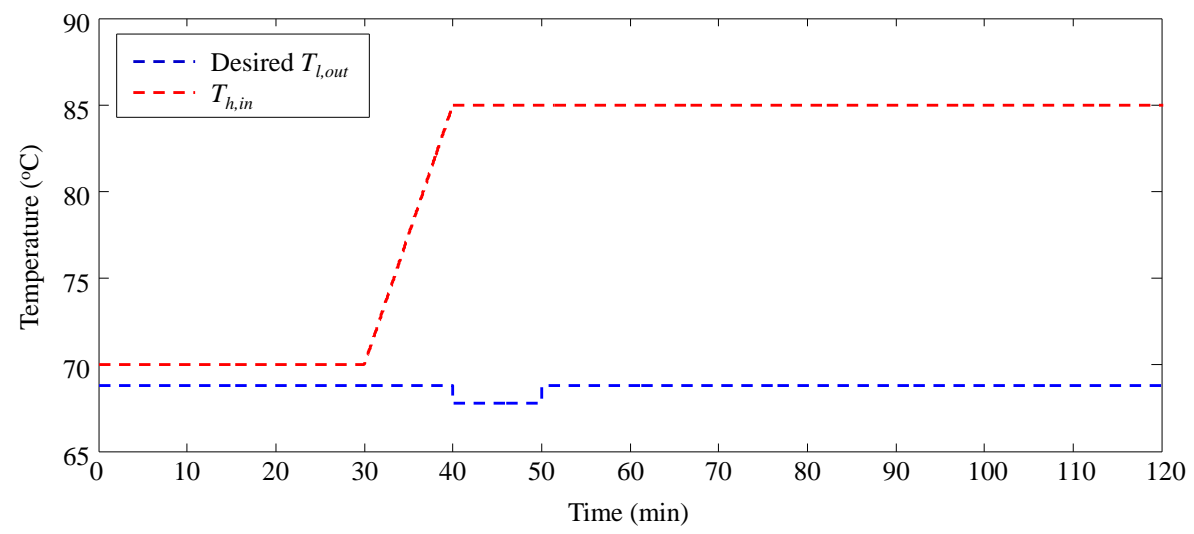




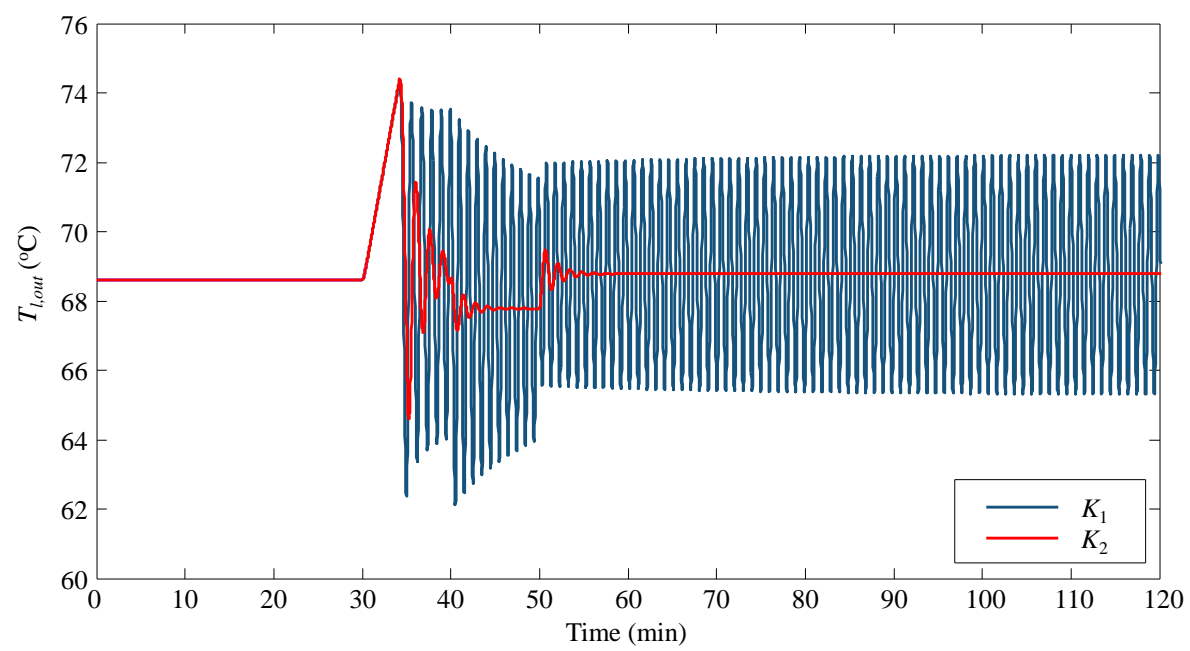

544

545

546

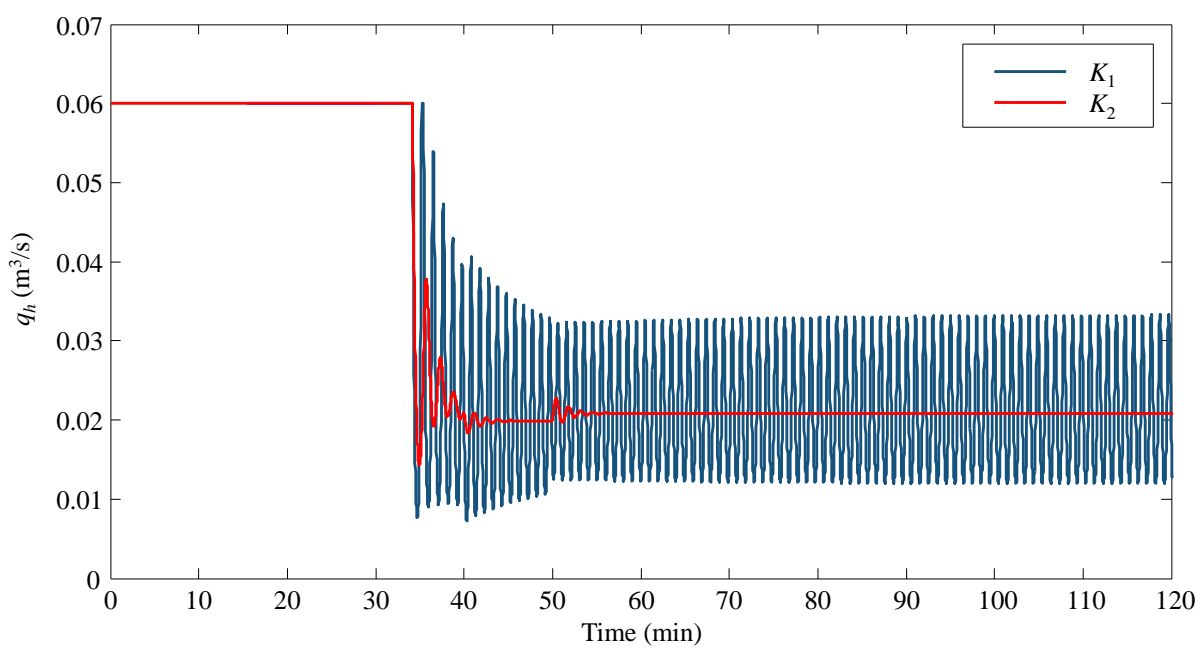

(c)

549 Fig. 18. Dynamic responses in worse operating condition under the control of $K_{1}$ and $K_{2}$ (with $T_{l, \text { in }}=40{ }^{\circ} \mathrm{C}, q_{l}=0.03 \mathrm{~m}^{3} / \mathrm{s}$ ). (a) Variation of desired $T_{l, o u t}$ and $T_{h, \text { in }}$. (b) Responses of $q_{h}$. (c) 
Based on the nonlinear ODE model, the linearized model of plate heat exchanger for controller design and stability analysis was derived. The nonlinear ODE model of plate heat exchanger was solved with Simulink. In order to validate the nonlinear plate heat exchanger model, the parameters and measured data provided in Ref. [16] were adopted in simulation. The simulated results were compared with the measured operation stability criterion of district heating substation at all operating conditions.

The dynamic responses of heating substation under the control of a PI controller tuned at a certain operating condition were analyzed. And the operation stability of heating

(1) Comparison of the measured data and simulated results of the plate heat exchanger shows that the proposed nonlinear ODE model has satisfactory accuracy in describing the thermal dynamics of plate heat exchanger. Relative errors of the two outlet temperatures: $T_{h, \text { out }}$ and $T_{l, \text { out }}$ are both varying within $\pm 8 \%$.

(2) Simulation results of heating substation control system indicate that the controller tuned at a certain operating condition may be unstable, when operating condition changes in large range. For example, the operation instability of district heating substation may occur at the high primary supply temperature, if the controller is tuned at low primary supply temperature. 
576

(3) With the proposed stability criterion for heating substation operation, the controller can be retuned to be stable at all operating conditions.

Since operation stability of heating substation is the basic requirement of the operation and is of great importance to energy conservation of pumping system, reducing the failure rate of control valve and improving the heating quality of the secondary system, the proposed method will be very helpful and applicable to heating substation controller tuning and operation stability analysis for stable operation.

\section{Appendix A. Calculation of heat transfer coefficient $k$}

The overall heat transfer coefficient of plate heat exchanger can be determined by the following formula:

$$
k=\left(\frac{1}{k_{h}}+\frac{1}{k_{p}}+\frac{1}{k_{l}}\right)^{-1}
$$

where $k_{p}=\frac{\lambda_{p}}{d_{p}}$ is the heat transfer coefficient of the plate. $k_{h}$ and $k_{l}$ are determined by the following formulas [16]:

$$
\begin{aligned}
& k_{h}=\frac{N u_{h} \lambda_{h}}{D}, N u_{h}=C_{N u} \cdot R e_{h}^{n_{1}} \cdot P r_{h}^{n_{2}}, R e_{h}=\frac{\rho D q_{h}}{\mu_{h} M b d}, P r_{h}=\frac{\mu_{h} c_{p}}{\lambda_{h}} \\
& k_{h}=\frac{N u_{h} \lambda_{h}}{D}, N u_{l}=C_{N u} \cdot R e_{l}^{n_{1}} \cdot P r_{l}^{n_{2}}, R e_{l}=\frac{\rho D q_{l}}{\mu_{l} M b d}, P r_{l}=\frac{\mu_{l} c_{p}}{\lambda_{l}}
\end{aligned}
$$

where $D=2 d$ is the hydraulic diameter; $\lambda_{h}$ and $\lambda_{l}$ are the heat conductivities of the high temperature side water and the low temperature side water, respectively; $N u_{h}$ and $N u_{l}$ are the Nusselt numbers of the two sides; $C_{N u}, n_{1}$ and $n_{2}$ are empirical parameters provided by the manufacturer; $R e_{h}$ and $R e_{l}$ are the Reynolds numbers of the two sides; $P r_{h}$ and $P r_{l}$ are the Prandtl numbers of the two sides; $\mu_{h}$ and $\mu_{l}$ are the dynamic viscosities of the two sides. 


\section{Appendix B. Linearized plate heat exchanger model}

600

601

602

603

604

605

606

607

608

ODE model of plate heat exchanger Eq. (8) and (9). Then define

$$
\begin{aligned}
A_{11}= & \left(\begin{array}{llllll}
a_{1} & a_{2} & & & & \\
& a_{1} & a_{2} & & & \\
& & a_{1} & a_{2} & & \\
& & & \ddots & \ddots & \\
& & & & a_{1} & a_{2}
\end{array}\right), A_{12}=\left(\begin{array}{llllll}
a_{3} & & & & & \\
& a_{3} & & & & \\
& & a_{3} & & \\
& & & \ddots & & \\
& & & a_{3} & \\
& & & & & a_{1}
\end{array}\right) \\
A_{21}= & \left(\begin{array}{llllllll}
a_{4} & & & & & \\
& a_{4} & & & & \\
& & a_{4} & & & \\
& & & \ddots & & \\
& & & & a_{4} & \\
& & & & & a_{4}
\end{array}\right), A_{22}=\left(\begin{array}{llllll}
a_{6} & & & & & \\
a_{5} & a_{4} & & & & \\
& a_{5} & a_{4} & & & \\
& & a_{5} & \ddots & & \\
& & & \ddots & a_{4} & \\
& & & & a_{5} & a_{4}
\end{array}\right)
\end{aligned}
$$

where $\bar{k}, \bar{q}_{h}, \bar{q}_{l}, \bar{T}_{l, j}$ and $\bar{T}_{h, j}$ are the equilibrium point values of the nonlinear

609 and

$$
\begin{aligned}
& 610 \quad A=\left(\begin{array}{ll}
A_{11} & A_{12} \\
A_{21} & A_{22}
\end{array}\right) \\
& 611 \quad T=\left(\begin{array}{llllllll}
T_{h, 1} & T_{h, 2} & \cdots & T_{h, N} & T_{l, 1} & T_{l, 2} & \cdots & T_{l, N}
\end{array}\right)^{\mathrm{T}} \\
& 612 \quad B_{1}=\left(b_{11,1}, b_{11,2}, \ldots, b_{11, j}, \ldots, b_{11, N}, b_{21,1}, b_{21,2}, \ldots, b_{21, j}, \ldots, b_{21, N}\right)^{\mathrm{T}} \\
& 613 \quad B_{2}=\left(b_{12,1}, b_{12,2}, \ldots, b_{12, j}, \ldots, b_{12, N}, b_{22,1}, b_{22,2}, \ldots, b_{22, j}, \ldots, b_{22, N}\right)^{\mathrm{T}} \\
& 614 \quad B_{3}=\left(O_{1 \times(N-1)}, a_{2}, O_{1 \times N}\right)^{\mathrm{T}} \\
& 615 \quad B_{4}=\left(O_{1 \times N}, a_{5}, O_{1 \times(N-1)}\right)^{\mathrm{T}}
\end{aligned}
$$




$$
C=\left(O_{1 \times N}, O_{1 \times(N-1)}, 1\right)
$$

617

where $A_{11}, A_{12}, A_{21}$ and $A_{22}$ are $N \times N$ matrices. $T, B_{1}, B_{2}, B_{3}$ and $B_{4}$ are $2 N$-dimensional vectors.

The transfer function form of the linearized plate heat exchanger model is:

$$
T_{l, \text { out }}=G(s) q_{h}+G_{d, 1}(s) q_{l}+G_{d, 2}(s) T_{h, \text { in }}+G_{d, 3}(s) T_{l, \text { in }}
$$

where

$$
\begin{aligned}
& G(s)=C(s I-A)^{-1} B_{1} \\
& G_{d, 1}(s)=C(s I-A)^{-1} B_{2} \\
& G_{d, 2}(s)=C(s I-A)^{-1} B_{3} \\
& G_{d, 3}(s)=C(s I-A)^{-1} B_{4}
\end{aligned}
$$

\section{Acknowledgement}

This work was supported by the State Oceanic Administration of China (Grant No. cxsf-43); and the National Natural Science Foundation of China (No. 51106110).

\section{Reference}

[1] Building energy conservation research center of Tsinghua University, The annual development research report of China building energy conservation, 2015 ed., Building Industry Press, Beijing, 2015. (in Chinese)

[2] J. Gustafsson, J. Delsing, J.V. Deventer, Improved district heating substation efficiency with a new control strategy, Appl. Energy 87(2010) 1996-2004. 
639 [3] J. Gustafsson, J. Delsing, J. V. Deventer, Experimental evaluation of radiator 640 control based on primary supply temperature for district heating substations, Appl. 641 Energy 88(2011) 4945-4951.

642 [4] H. Gadd, S. Werner, Achieving low return temperatures from district heating 643 substations, Appl. Energy 136(2014) 59-67.

644 [5] H. Gadd, S. Werner, Fault detection in district heating substations, Appl. Energy $645 \quad 157(2015) 51-59$.

646

647

[6] M. Brand, J.E. Thorsen, S. Svendsen, Numerical modelling and experimental measurements for a low-temperature district heating substation for instantaneous preparation of DHW with respect to service pipes, Energy 41(2012) 392-400.

[7] M. Brand, A.D. Rosa, S. Svendsen, Energy-efficient and cost-effective in-house substations bypass for improving thermal and DHW (domestic hot water) comfort in bathrooms in low-energy buildings supplied by low-temperature district heating, Energy 67(2014) 256-267.

[8] M. Kuosa, M. Aalto, M.E.H. Assad, et al., Study of a district heating system with the ring network technology and plate heat exchangers in a consumer substation, Energy Build. 80(2014) 276-289.

[9] L. Dobos, J. Abonyi, Controller tuning of district heating networks using experiment design techniques, Energy 36(2011) 4633-4639.

[10] S.K. Al-Dawery, A.M. Alrahawi, K.M. Al-Zobai Dynamic modeling and control of plate heat exchanger, Int. J. Heat Mass Tran., 55(2012) 6873-6880.

[11] A. Michel, A. Kugi, Model based control of compact heat exchangers independent of the heat transfer behavior, J. Process Contr., 24(2014)286-298.

[12] G.F. Franklin, D.J. Powell, A. Emami-Naeini, Feedback Control of Dynamic Systems, seventh ed., Pearson, New York, 2015. 
664 [13] P. Andersen, T.S. Pedersen, J. Stoustrup, et al., Proceedings of the 2000 American

665 Control Conference. ACC (IEEE Cat. No.00CH36334), Chicago, IL, 2000, pp. $666 \quad 135-139$ vol.1.

667 [14] Tahersima F, Stoustrup J, Rasmussen H. An analytical solution for 668 stability-performance dilemma of hydronic radiators, Energy Build. 64(2013) $669 \quad 439-446$.

670 [15] Y. Wang, S. You, X. Zheng, H. Zhang, Accurate model reduction and control of 671 radiator for performance enhancement of room heating system, Energy Build $672 \quad 138(2017) 415-431$.

673 [16] A. Michel, A. Kugi, Accurate low-order dynamic model of a compact plate heat 674 exchanger, Int. J. Heat Mass Tran. 61(2013) 323-331.

675 [17] S. Skogestad, I. Postlethwaite, Multivariable Feedback Control: Analysis and 676 Design, second ed., Wiley, New York, 2007.

677 [18] American Society of Heating, Air-Conditioning Engineers, ASHRAE handbook: 678 heating, ventilating, and air-conditioning systems and equipment, SI ed; 2012. 679 680 681 682 683 684 